\title{
Stem cells living with a Notch
}

\author{
Ute Koch, Rajwinder Lehal and Freddy Radtke*
}

\begin{abstract}
Summary
Notch signaling has been shown over the past few decades to play fundamental roles in a plethora of developmental processes in an evolutionarily conserved fashion. Notch-mediated cell-tocell signaling is involved in many aspects of embryonic development and control of tissue homeostasis in a variety of adult tissues, and regulates stem cell maintenance, cell differentiation and cellular homeostasis. The focus of this Review is the role of Notch signaling in stem cells, comparing insights from flies, fish and mice to highlight similarities, as well as differences, between species, tissues and stem cell compartments.
\end{abstract}

Key words: Notch, Differentiation, Fate decisions, Self-renewing tissues, Stem cells

\section{Introduction \\ Stem cells and Notch signaling - from simplicity to complexity}

Tissue stems cells (SCs) exist in most embryonic and adult organisms, and are generally defined as cells having self-renewing capacity, as well as the ability to generate all cell types of a given organ. During development, they give rise to all lineages of the particular tissue, whereas in the adult they are responsible for maintaining tissue homeostasis and can be activated after injury in order to regenerate damaged tissues. The balance between selfrenewal and differentiation is under stringent control to allow proper development and avoid uncontrolled growth, which in its severest form can lead to cancer. Extensive research on somatic SCs has revealed that these processes are regulated by a limited number of evolutionary conserved signaling cascades - one of which is the Notch signaling pathway (Box 1 and Table 1). In this Review, we describe the functional implications of the Notch cascade in SCs of different self-renewing tissues, contrasting and comparing different species. Although Notch function has been implicated in many tissues, we focus here primarily on the nervous system, muscle, intestine and the hematopoietic system, where the pathway has proven to be particularly important for the development of SCs, their maintenance and/or function.

\section{The Notch signaling pathway is highly context and tissue specific}

The Notch cascade has a unique mode of action and has been recognized as one of a few signaling pathways that are repeatedly used in multiple developmental processes in embryonic and adult tissues. The details of the signaling mechanism have been comprehensively reviewed previously (see Bray, 2006; Kopan and Ilagan, 2009; Fortini, 2012). A simplified summary of the Notch pathway is given in Box 1 and Fig. 1. Despite the apparent simplicity

Ecole Polytechnique Fédérale de Lausanne (EPFL), School of Life Science, Swiss Institute for Experimental Cancer Research (ISREC), Station 19, 1015 Lausanne, Switzerland.

*Author for correspondence (freddy.radtke@epfl.ch) of this pathway, or maybe because of it, Notch receptors and ligands are influenced by a broad spectrum of post-translational modifications and other cellular processes that strongly modulate Notch pathway activity in specific developmental contexts. It is this context specificity of Notch activation that dictates the specific process or function triggered, such as differentiation, proliferation or apoptotic events. This context-dependent Notch activity can therefore drive numerous aspects of the development of multicellular eukaryotic organisms, and has recently been linked to stem cell fate and maintenance in embryonic and adult tissues (Liu et al., 2010a; Bigas and Espinosa, 2012).

\section{The nervous system}

Notch in neural SC development and cell fate decisions

Studies in Drosophila have frequently given rise to important paradigms for self-renewal and differentiation processes in vertebrates. Indeed, the first evidence that Notch signaling might be involved in regulating neural SCs (NSCs) and downstream lineage decisions came from early studies in fruit flies. During the development of the central and peripheral nervous systems (CNS, PNS) of Drosophila, Notch signaling specifies individual cells among an equipotent cluster in the ectoderm to become neural progenitors: neuroblasts (NBs) in the CNS (Artavanis-Tsakonas et al., 1991) or sensory organ precursor (SOP) cells in the PNS (Furukawa et al., 1992; Schweisguth and Posakony, 1992). Segregation of NB and SOP cell lineages is initiated by a stochastic event that results in individual cells that express higher levels of

\section{Box 1. An overview of the Notch pathway}

The canonical Notch pathway uses paracrine cell-to-cell contact and converts this interaction directly into changes of gene expression. Notch signaling is initiated through the interaction of a receptor on the signal-receiving cell and a ligand on the neighboring signalsending cell (see Table 1 for receptors, ligands and DNA-binding components of different specie). Upon binding to any of the DeltaSerrate LAG2 (DSL) ligands, the Notch receptor is activated by a cascade of proteolytic cleavages (Bray, 2006; Kopan and Ilagan, 2009). Crucially, $\gamma$-secretase-mediated release of the Notch intracellular domain (NICD) from the cell membrane results in its translocation into the nucleus to induce target gene transcription, via interactions with DNA-binding proteins of the CSL family (CBF1 or RBPJ in humans; Suppressor of hairless [Su(H)] in Drososphila; LAG in Caenorhabitis elegans; RBP-J in the mouse) (Table 1) (Bray, 2006). Although there are multiple Notch target genes, the bestcharacterized are the basic helix-loop-helix (bHLH) transcriptional repressors of the Hairy enhancer of split (Hes) and Hairy-related (Hrt) protein families (Iso et al., 2003).

In recent years, there has been increasing evidence of Notch signaling events, which neither require the classical DSL ligands nor the CSL transcriptional mediator complex. In addition, other noncanonical signals such as signal transduction without receptor cleavage or crosstalk with other signaling pathways have gained more interest. An in depth discussion of these non-canonical mechanisms is beyond the scope of this Review but can be found elsewhere (Heitzler, 2010). 


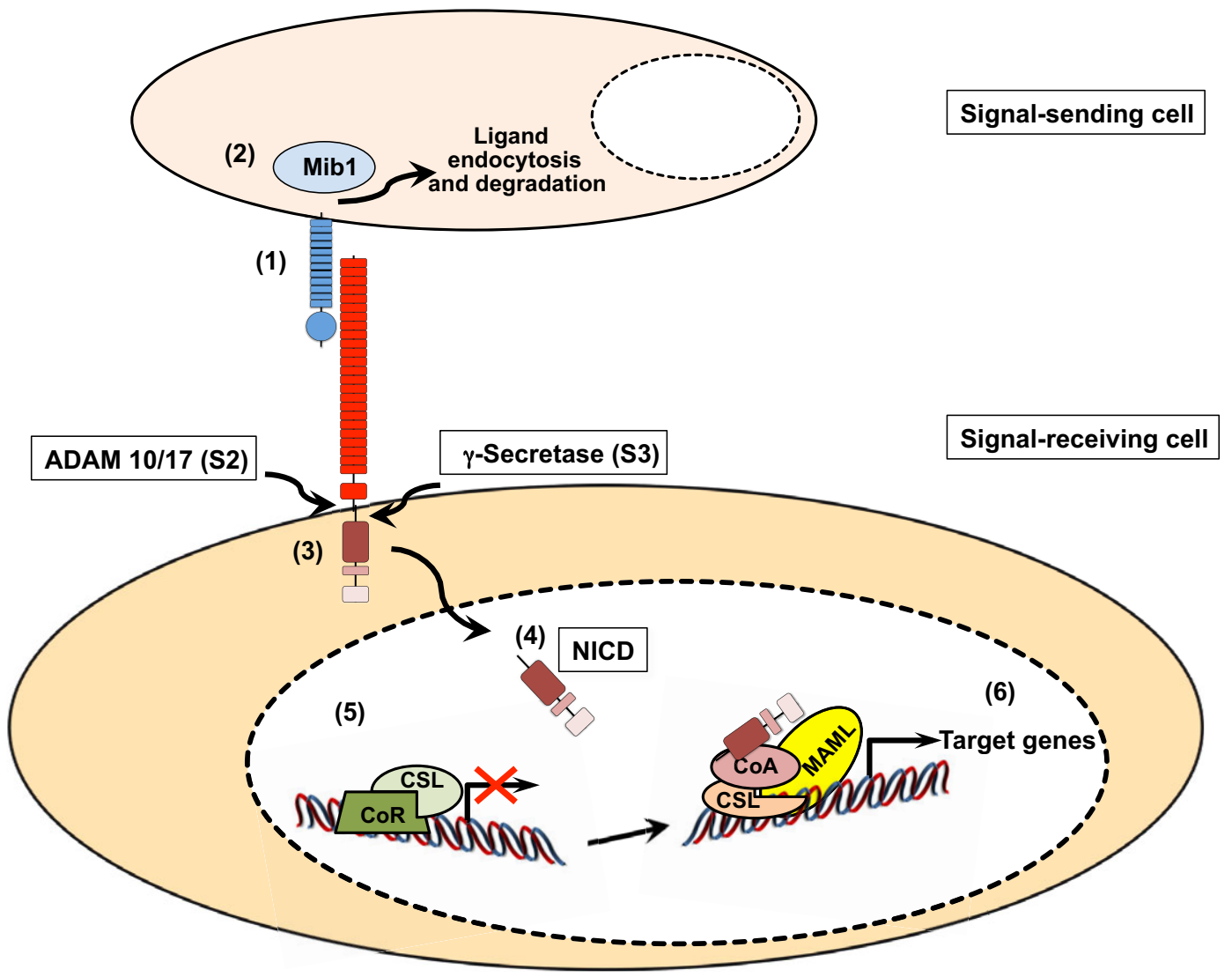

Fig. 1. Canonical Notch signaling. A Notch ligand expressed on the surface of a signal-sending cell interacts with a Notch receptor on the signalreceiving cell, triggering Notch receptor activation (1). The E3 ubiquitin ligase mindbomb 1 (Mib1) promotes ligand endocytosis and is required for efficient Notch receptor activation (2). The trans-interaction between ligand and receptor induces two consecutive proteolytic cleavages of the heterodimeric Notch receptor (3). The first cleavage is mediated by the metalloprotease ADAM10/17 (S2 cleavage), followed by a second cleavage through the $\gamma$-secretase complex (S3 cleavage). These cleavages lead to the generation of a free intracellular domain (NICD), which translocates to the nucleus of the signal-receiving cell (4). In the absence of NICD (5), a transcriptional repressor complex composed of CSL and additional corepressors (CoR), such as N-CoR, keeps Notch target genes silent. The interaction of NICD with CSL (6) dissociates the repressor complex and leads to the recruitment of MAML and additional co-activators (CoA, e.g. p300) to the complex. The assembly of this transcriptional activation complex on the promoter regions of Notch target genes leads to an upregulation of gene expression.

the Notch ligand Delta compared with their neighbors. Thereafter, activation of the Notch cascade in these surrounding cells leads to the repression of proneural genes in the presumptive non-neuronal cell. As Delta expression is itself regulated by proneural transcription factors, this creates a feedback loop that maintains proneural gene expression in the Delta-expressing cell, and no expression of these factors in the neighboring non-neuronal cells (Artavanis-Tsakonas et al., 1991; Bray, 1998). In developing embryos that lack Notch function, all the cells within the proneural cluster develop into NBs or SOP cells, thus presenting a neurogenic phenotype (Poulson, 1937; Knust and Campos-Ortega, 1989). As fate specification is mediated via cell-to-cell signaling between adjacent cells, this process is referred to as 'lateral inhibition' or 'lateral cell fate specification' (Fig. 2A).

These early studies showed that Notch functions to specify a specific cell fate between equipotent cells that could adopt at least two fates. However, it also fostered the view that Notch might have the potential to inhibit differentiation and thereby preserve stem or progenitor cells. In agreement with this, overexpression of Delta 1 in early Xenopus embryos (Coffman et al., 1993) or in the developing chick retina (Henrique et al., 1997) inhibited neuron production, while expression of a dominant-negative form of Delta 1 caused excess production of neurons (Austin et al., 1995; Chitnis et al., 1995; Henrique et al., 1995; Henrique et al., 1997). Activation of Notch signaling in rat retinal progenitors also inhibited differentiation but induced expression of Müller glia markers and caused abnormal growth (Bao and Cepko, 1997), suggesting that Notch may block neuronal differentiation, but promotes proliferation as well as some aspects of glial differentiation (see below). These were among the first studies in vertebrates to show that Delta-Notch signaling controls the 'choice' of a cell to remain as a progenitor or to differentiate into a neuron. More recent analyses in the vertebrate retina have expanded on these earlier observations to introduce a spatial component to our understanding of how Notch signaling is regulated (see Box 2).

Additional evidence supporting the proposal that Notch signaling inhibits neuronal differentiation is derived from conditional genetic loss- and gain-of-function approaches in the developing mouse brain. Conditional inactivation of Notch1 in the midbrain-hindbrain region of the neural tube results in precocious neural differentiation followed by apoptosis, reducing the number of neurons in the cerebellum. Formation of glial cells is also 
Table 1. Across species: the basic components of the Notch signaling pathway

\begin{tabular}{|c|c|c|c|c|}
\hline Notch pathway component & C. elegans & D. melanogaster & D. rerio & M. musculus \\
\hline \multirow[t]{7}{*}{ Ligand (sending cell) } & LAG-2 & Delta & DeltaA (Dla) & Delta-like 1 (DII1) \\
\hline & APX-1 & & DeltaB (Dlb) & Delta-like 3 (DII3) \\
\hline & ARG-2 & & DeltaC (DIC) & Delta-like 4 (DII4) \\
\hline & F26B12.2 & & DeltaD (Dld) & \\
\hline & & & DII-4 & \\
\hline & & Serrate & Jagged 1a & Jagged 1 (Jag1) \\
\hline & & & Jagged $1 b$ & Jagged 2 (Jag2) \\
\hline \multirow{4}{*}{ Receptor (receiving cell) } & IN 12 & Netch & Jaggea 2 & Notch 1 \\
\hline & LIIN-12 & INOLCh & Notch Ia & Notch 1 \\
\hline & & & Notch1b & Notch2 \\
\hline & & & $\begin{array}{l}\text { Notch2 } \\
\text { Notch } 3\end{array}$ & Notch3 \\
\hline \multirow[t]{2}{*}{ DNA-binding protein (CSL) } & LAG-1 & Suppressor of Hairless [Su(H)] & RBP-J & RBP-J (CBF) \\
\hline & & & & RBP-Jl \\
\hline $\begin{array}{l}\text { Notch ligands, Notch receptors a } \\
\text { musculus are shown. }\end{array}$ & n factors & ents species. & ila & erio and Mus \\
\hline 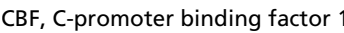 & & & & \\
\hline
\end{tabular}

affected (Lütolf et al., 2002). Likewise, loss of progenitors and premature differentiation was noticed in mice with conditional ablation of either Notch1 or RBP-J in neural progenitors (Yang et al., 2004; Imayoshi et al., 2010). A similar phenotype was also observed upon neocortex-specific inactivation of mindbomb, an E3 ubiquitin ligase necessary for ligand internalization in signalsending cells and Notch activation upon ligand-receptor interaction (Itoh et al., 2003; Koo et al., 2005; Yoon et al., 2008a). The combined results of all these Notch pathway mutants support the classic view that Notch functions to inhibit neural differentiation, thereby preserving the neural stem/progenitor pool during brain development.

Reciprocal gain-of-function experiments expressing a dominantactive form of Notch1 or target genes of the Hes family (Hes1, Hes5, Hey1 or Hey2) in the developing forebrain of the mouse not only confirmed that Notch signaling inhibits neuronal differentiation, but also revealed its ability to promote a glial cell fate (Ishibashi et al., 1994; Gaiano et al., 2000; Ohtsuka et al., 2001; Sakamoto et al., 2003). Postnatal analysis of mice in which Notch was ectopically activated during embryonic brain development revealed the presence of dispersed and periventricular astrocytes, suggesting that after inhibiting differentiation, Notch might function instructively to promote the astrocyte lineage (Gaiano et al., 2000; Chambers et al., 2001). Impaired gliogenesis in Rbpj mutant mice (Taylor et al., 2007) and additional work in fish and mice indicate that Notch indeed promotes the astroglia lineage, while oligodendrocyte differentiation is inhibited (Wang et al., 1998; Grandbarbe et al., 2003; Park and Appel, 2003) - a role that is apparently independent of Notch function in the maintenance of undifferentiated neuronal progenitors. Yet, whether Notch specifies a bipotent glial progenitor to adopt an astroglial, as opposed to oligodendrocyte, fate (Grandbarbe et al., 2003) is currently unclear (see below). By contrast, work from zebrafish showed that conditional expression of a dominant-active Notch promotes the formation of excess oligodendrocyte progenitors in the ventral spinal cord. This suggests that Notch promotes oligodendrocyte precursor cell fate but inhibits subsequent terminal differentiation (Park and Appel, 2003) (Fig. 2B).

Together, these data demonstrate that Notch functions at different levels and at different times during CNS development. Initially, Notch promotes precursor proliferation and inhibits neuronal differentiation while promoting glial cell fate. Subsequently, Notch promotes differentiation of astrocytes and inhibits terminal differentiation of oligodendrocytes (Fig. 2B). Although these basic functions apply in all vertebrates, there do appear to be species-specific differences in the precise roles of the pathway in regulating cell proliferation and fate (see Table 2A,B).

\section{Notch, asymmetric division and binary decisions}

In addition to confirming the importance of Notch in self-renewal and lineage specification, early work in Drosophila established its role in asymmetric cell division, and how this links to fate choice. In this context, asymmetric cell division defines a process in which the unequal distribution of cell fate determinants results in the generation of daughter cells with two different fates or properties (Neumüller and Knoblich, 2009). One of the classical examples is in the PNS of Drosophila. Once a SOP cell has been generated within the proneural cluster in the ectoderm, it undergoes three rounds of asymmetric cell division to form the different cell types of a sensory bristle (Bardin et al., 2004). Asymmetric Notch signaling is essential for inducing binary cell fate decisions in the PNS; these fate choices are concomitantly regulated through asymmetric distribution of the Notch inhibitor Numb (Jan and Jan, 1994) (Fig. 3A,B).

These and other results led to the general paradigm that Notch influences binary cell fate decisions from bi-potent progenitor cells. However, a recent study in the developing zebrafish brain (Dong et al., 2012) showed that this concept of asymmetric division could also apply to the regulation of self-renewal versus differentiation within the same lineage - in this case, radial glial cells. The vast majority of radial glia cells undergo asymmetric cell division within the developing CNS, generating a basal self-renewing daughter and an apical cell that is prone to differentiate (reviewed by Egger et al., 2011). In vivo time-lapse imaging at single cell resolution combined with clonal analysis of individual radial glial lineages revealed that Notch regulates this differential fate (Dong et al., 2012). Asymmetric cell division in this system is established by the intrinsic polarity regulator partitioning defective protein 3 (Par3). Par3 segregates mindbomb to the apical daughter cell and thereby restricts Notch signaling to the basal daughter cell. The resultant differential Notch activity promotes self-renewal in the basal cell (high Notch) and differentiation of the apical daughter (low Notch) (Fig. 3C). This elegant study illustrates how selfrenewal and differentiation segregates in asymmetrically dividing neural stem/progenitor cells of the same lineage. 

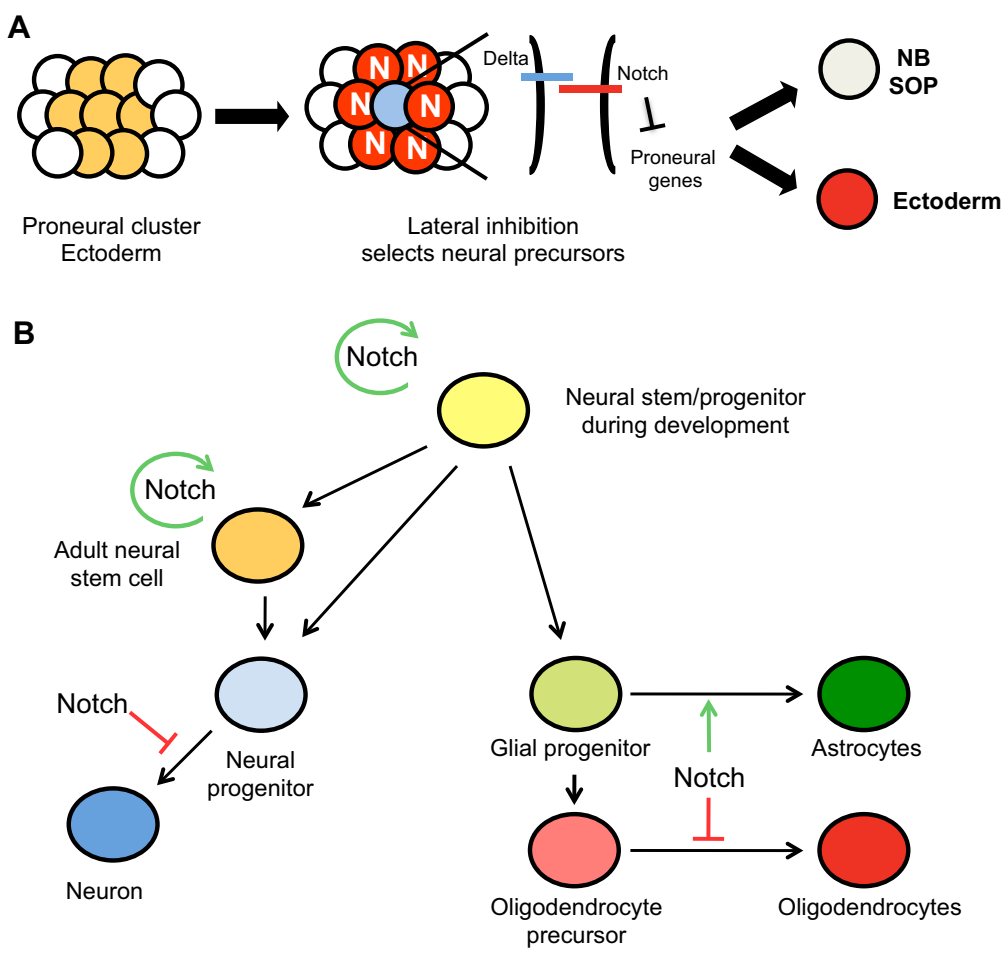

Fig. 2. Notch function in the developing nervous system of Drosophila and vertebrates. (A) Lateral inhibition within the developing nervous system of Drosophila. The role of Notch signaling during selection of neuroblasts (NBs) in the CNS or sensory organ precursor (SOP) cells in the peripheral nervous system from a proneural cluster of equipotent cells is shown (yellow). These equipotent cells express the same amount of receptors and ligands. Thus, Notch signaling levels are equal among individual cells within the cluster. As a result of a stochastic event, individual cells within the cluster start expressing higher levels of Notch ligands (blue). More ligands on the cell surface (blue) can now engage more receptors in neighbouring cells (red) and thereby elicit a stronger Notch signal compared with the ligand-expressing cell (blue). Notch signal receiving cells (red) are inhibited from developing into either a NB or SOP cell, and therefore differentiate into ectoderm (red). By contrast, Delta-like-expressing cells (blue, Notch signal initiating cells) will adopt either a NB or SOP cell fate. At the molecular level, Notch signaling results in the repression of proneural genes. Proneural genes will only be activated in neuroectodermal cells that have low or no Notch signaling and as a result become NBs or SOP cells. (B) Notch signaling regulates self-renewal (curved green arrows) of developing and adult neural stem cells, preserving the neural stem cell pool. Notch also promotes gliogenesis (straight green arrow), whereas oligodendrocyte and terminal differentiation of neurons are inhibited (red capped bars).

\section{Notch: a key regulator of adult NSCs}

In the postnatal or adult brain, NSCs are found in the subventricular zone (SVZ) and the subgranular zone (SGZ), and continue to produce neural cells throughout life. Notch components, although broadly expressed throughout brain tissue, are also found in cells of the SVZ and the SGZ, suggesting that Notch might regulate postnatal NSCs (Stump et al., 2002; Irvin et al., 2004; Givogri et al., 2006). Consistent with this possibility, Notch activity was detected in postnatal or adult NSCs using different reporter mice (Ehm et al., 2010; Imayoshi et al., 2010; Lugert et al., 2010; Smith et al., 2012). Conditional gain- and loss-of-function studies

\section{Box 2. Notch signaling moving in waves}

More recent work from the zebrafish retina has provided a deeper geometric understanding of how Notch signaling is triggered between ligand-expressing neurons and receptor-expressing progenitors (Del Bene et al., 2008). The nuclei of retinal progenitors move between the apical and basal surfaces of the neuroepithelium in phase with their cell cycle, a process known as interkinetic nuclear migration (INM). Interestingly, Notch receptors and ligands are expressed in a graded fashion along the apicobasal axis, such that Notch receptor expression is higher apically, whereas ligand expression predominates in the basal region of cells. Consistent with this expression pattern, Notch activity is highest on the apical side of the neuroepithelium. Zebrafish mutants with altered INM, where nuclei migrate faster and deeper into the basal part of the neuroepithelium, will receive fewer Notch signals, resulting in premature cell cycle exit and increased neuronal differentiation (Del Bene et al., 2008). Additional work on the zebrafish retina suggested that Notch signaling is not only influenced by the apicalbasal polarity of the neuroepithelium, but that Notch itself is involved in setting up this polarity (Ohata et al., 2011). In view of these data, it is tempting to speculate that such polarity of the neuroepithelium is used to coordinate Notch signaling with cell division and differentiation within the spatial context of the developing tissue. demonstrated that Notch regulates quiescence and cell cycle exit of NSCs. In the telencephalic germinal zone of the adult zebrafish, NSCs transit between quiescence and proliferation. High Notch activity was shown to maintain NSCs in a quiescent state, whereas blocking Notch resulted in immense NSC division followed by differentiation and increased numbers of adult-born neurons, leading to an exhaustion of the NSC pool (Chapouton et al., 2010). This study also suggested that Notch signaling in NSCs might be controlled by a lateral inhibition-like mechanism, resulting in equilibrium between NSC quiescence and generation of proliferating progenitors. Similar results were obtained in mice with conditional ablation of RBP-J in the adult brain, leading to differentiation of all NSCs into transit-amplifying cells and neurons. As a result, neurogenesis increased transiently, but later all NSCs were depleted and neurogenesis was completely lost (Ehm et al., 2010; Imayoshi et al., 2010). These results indicate an absolute requirement of Notch signaling for the maintenance of NSCs and a for the proper control of neurogenesis in both embryonic and adult brains.

Little is known about how Notch signaling within the NSC niche is regulated. Jagged 1 (Jag1) is expressed on ependymal cells and astrocytes, and is necessary for NSC maintenance in the early postnatal brain, implicating ependymal cells and astrocytes as niche components (Nyfeler et al., 2005). It therefore is likely that Jag1 activates Notch1 on NSCs, thus preventing differentiation and SC exhaustion. The Delta-like 4 ligand also appears to promote the generation of neural precursor cells in the adult rat brain (Androutsellis-Theotokis et al., 2006). Another study suggested that NSCs could be regulated through crosstalk between the epidermal growth factor receptor (EGFR) and Notch signaling pathways (Aguirre et al., 2010). Transgenic mice overexpressing EGFR in neural progenitors have increased numbers of transient amplifying cells, presumably as a consequence of EGFR-induced cell expansion. Interestingly, this correlated with reduced NSC number and self-renewal. Moreover, the study showed that EGFR- 
Table 2. Notch signaling in different somatic stem cells - mechanisms and strategies

\begin{tabular}{|c|c|c|c|}
\hline \multicolumn{4}{|c|}{ A Developing embryo } \\
\hline Organism & Neuronal stem cell & Muscle stem cell & Intestina \\
\hline Drosophila & $\begin{array}{l}\text { Notch signaling specifies } \\
\text { individual cells to become } \\
\text { neural progenitors - either } \\
\text { NBs in the CNS or SOP cells in } \\
\text { the PNS } \\
\text { Notch signaling specifies } \\
\text { alternative cell fates through } \\
\text { asymmetric cell division }\end{array}$ & Not discussed & Not discussed \\
\hline Zebrafish & $\begin{array}{l}\text { Notch regulates self-renewal } \\
\text { versus differentiation } \\
\text { through asymmetric cell } \\
\text { division within the same } \\
\text { lineage } \\
\text { Notch signaling promotes } \\
\text { oligodendrocyte precursors } \\
\text { but inhibits terminal } \\
\text { differentiation }\end{array}$ & Not discussed & Not discussed \\
\hline Mouse & $\begin{array}{l}\text { Notch inhibits neuronal } \\
\text { differentiation in the } \\
\text { developing mouse brain, as } \\
\text { shown through loss-of- } \\
\text { function studies and gain-of- } \\
\text { function studies } \\
\text { Notch promotes differentiation } \\
\text { along the astrocyte lineage }\end{array}$ & $\begin{array}{l}\text { Notch promotes self-renewal } \\
\text { of Pax3/Pax7-positive } \\
\text { progenitor cells in the } \\
\text { dermomytome } \\
\text { Notch inhibits terminal } \\
\text { differentiation of muscle } \\
\text { progenitors by } \\
\text { transcriptional repression of } \\
\text { myogenic genes } \\
\text { Notch maintains a stem cell } \\
\text { niche for satellite cells } \\
\text { between the basal lamina } \\
\text { and plasma membrane of } \\
\text { the muscle myofibers }\end{array}$ & Not discussed \\
\hline
\end{tabular}

B Adult

\begin{tabular}{|c|c|c|c|c|}
\hline Organism & Neuronal stem cell & Muscle stem cell & Intestinal stem cell & Hematopoietic stem cell \\
\hline Drosophila & Not discussed & Not discussed & $\begin{array}{l}\text { ISCs express Delta ligand, } \\
\text { whereas EB cells express } \\
\text { Notch receptor } \\
\text { Notch regulates ISC self- } \\
\text { renewal and terminal } \\
\text { differentiation of EBs into } \\
\text { ECs }\end{array}$ & Not discussed \\
\hline Zebrafish & $\begin{array}{l}\text { Notch maintains NSC } \\
\text { quiescence }\end{array}$ & Not discussed & Not discussed & $\begin{array}{l}\text { Constitutive Notch signaling } \\
\text { expands hematopoietic } \\
\text { precursor cells }\end{array}$ \\
\hline Mouse/rat & Notch maintains NSCs & $\begin{array}{l}\text { Activation of Notch signaling } \\
\text { in mouse myoblasts inhibits } \\
\text { differentiation of } \\
\text { progenitors } \\
\text { RBP-J-mediated Notch } \\
\text { signaling regulates self- } \\
\text { renewal of Pax+ satellite } \\
\text { cells and represses myogenic } \\
\text { gene expression }\end{array}$ & $\begin{array}{l}\text { Notch signalling via Notch1 } \\
\text { and Notch2 receptors is } \\
\text { active in the ISCs, and } \\
\text { Paneth cells present DII4 } \\
\text { ligand } \\
\text { Notch signaling regulates } \\
\text { proliferation of ISCs and } \\
\text { their terminal differentiation } \\
\text { into an absorptive lineage in } \\
\text { the intestine }\end{array}$ & $\begin{array}{l}\text { Multiple genetic loss-of-function } \\
\text { studies revealed that Notch } \\
\text { signaling is not essential in } \\
\text { adult HSCS } \\
\text { HSCs can be expanded by } \\
\text { constitutive Notch activation in } \\
\text { vitro }\end{array}$ \\
\hline
\end{tabular}

The major functions of Notch signaling in selected stem cell compartments across different species.

AGM, aorta gonad mesonephros; CNS, central nervous system; DII4, Delta-like 4; EB, enteroblast; EC, enterocyte; HSCs, hematopoietic stem cell; ISCs, intestinal stem cell; LT-HSCs, long-term HSCs; NB, neuroblast; NSCs, neural stem cells; PNS, peripheral nervous system; SOP, sensory organ precursor.

expressing progenitor cells could suppress Notch signaling in NSCs by a non-cell autonomous process that leads to upregulation of Numb, the negative regulator of Notch. A reciprocal phenotype with reduced Numb levels and increased NSC self-renewal was observed in cells from waved 2 mutant mice, which carry a point mutation in the EGFR tyrosine kinase domain, resulting in decreased EGFR activity. This work thus clearly demonstrates that crosstalk between stem and progenitor cells is involved in
Wnt, Delta and Notch signaling pathways act separately, earlier and non cellautonomously across multiple cell types to induce HSCs

Notch signaling is dispensable for primitive hematopoiesis but regulates definite hematopoiesis mediated by the Runx1 transcription factor Notch signaling is not required to generate primitive hematopoietic progenitors in the yolk sac

Notch1 signaling is essential to generate definite HSCs from endothelial cells in the AGM and acts in a cell-autonomous way to generate definite LTHSCs

The Jag1 ligand and Notch1 receptor interaction within the AGM region is directly associated with definite HSC Generation. Whether expression of Dll1 or Dll4 in the AGM could also trigger sufficient Notch signaling remains unresolved. 
A

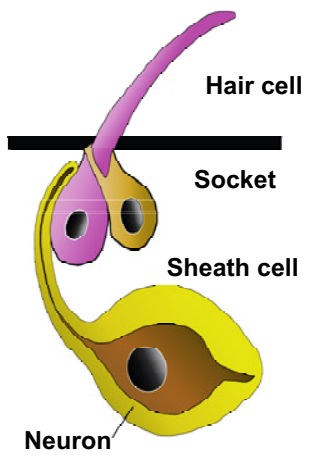

B

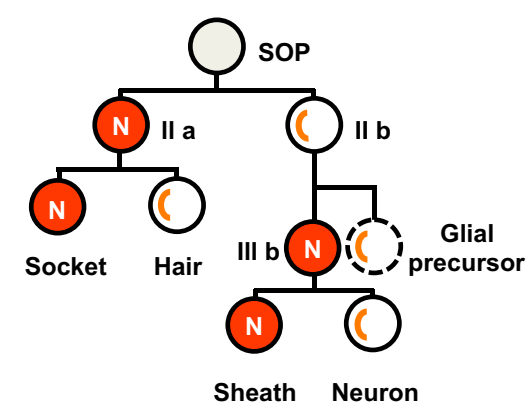

C

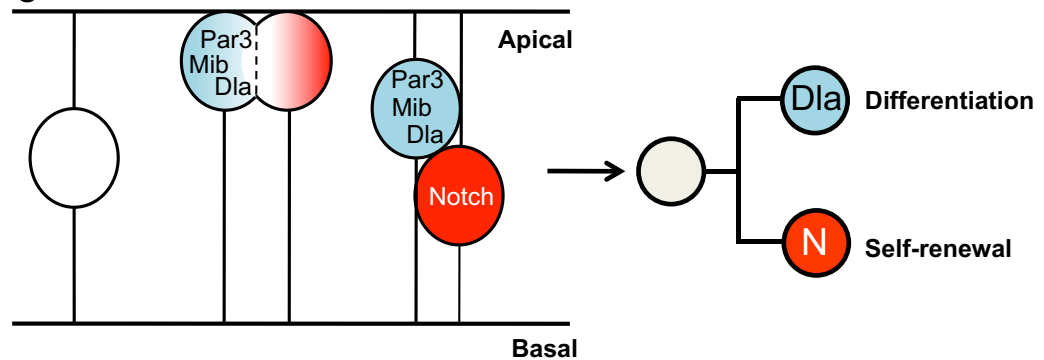

Fig. 3. Notch in asymmetrically dividing progenitor and stem cells. (A) A mechanosensory bristle of Drosophila consisting of four cells: a hair cell, a socket cell, a sheath cell and a neuron. (B) Once a sensory organ precursor (SOP) cell has been generated within the proneural cluster in the ectoderm it undergoes three rounds of asymmetric cell division to form the different cell types of a sensory bristle (Bardin et al., 2004). The first division gives rise to two cells (Ila and Ilb), then Ilb divides further into IIlb and into a glial cell that undergoes apoptosis. The final division of Ila generates the hair and socket cells (outer cells), while Illb gives rise to a neuron and a sheath cell (inner cells) of the terminally differentiated organ. Asymmetric Notch signaling $(\mathrm{N})$ is necessary at each cell division to specify cell fates: the Notch inhibitor Numb is asymmetrically distributed between the two daughter cells (orange), resulting in high Notch signaling in one daughter, and low activity in the other. (C) Notch-mediated regulation of self-renewal and differentiation of asymmetrically dividing radial glial cells in the developing zebrafish brain. During radial glial cell division, the ubiquitin E3 ligase mindbomb (Mib), which is necessary for ligand endocytosis, segregates to the apical daughter cell, through a process involving partitioning defective 3 (Par3). Asymmetric localization of mindbomb and a Delta ligand (Dla) induces Notch signaling in the more basal daughter cell. Basal cells with high Notch signaling self-renew, whereas more apical cells differentiate.

regulating cell homeostasis in the postnatal brain, and involves two specific signaling pathways (Aguirre et al., 2010).

Notch signaling has also been implicated in the stem cellmediated response to injury. Using an injury model of focal brain ischemia, administration of Delta-like 4, together with fibroblast growth factor 2 (FGF2), resulted in improved motor skills of injured rats. Control groups treated with either FGF2 or Delta-like 4 alone did not show any improved motor scores, suggesting that - at least in this particular model - Notch cooperates with FGF2 signaling to induce expansion of neural stem or progenitor cells after injury (Androutsellis-Theotokis et al., 2006).

Taken together, these studies clearly suggest that Notch is a gatekeeper of adult NSCs. However, Notch function in the adult brain goes beyond being a key regulator of NSCs, as it is involved in regulating migration, neurite outgrowth, survival and synaptic plasticity of neurons (for reviews, see Ables et al., 2011; Pierfelice et al., 2011).

\section{Notch and muscle SCs}

Neurogenic Notch mutations in Drosophila are known to cause muscle defects, indicating that Notch signaling is involved in the regulation of myogenesis (Poulson, 1937; Bate et al., 1993). This notion was reinforced almost two decades ago in studies using the mouse myoblast cell line $\mathrm{C} 2 \mathrm{C} 12$. Overexpression of the Notch intracellular domain (NICD) in $\mathrm{C} 2 \mathrm{C} 12$ myoblasts or their coculture with Jag1-expressing fibroblasts led to a block in muscle differentiation, preventing the formation of multinucleated myofibres (Kopan et al., 1994; Lindsell et al., 1995). These studies suggest that Notch signaling inhibits differentiation of early muscle progenitors as it does in neural precursors.

\section{Muscle development in vertebrates}

In vertebrates, muscle development occurs in three distinct phases: embryonic, fetal and postnatal. During embryonic development, muscle progenitors are derived from somites, which are compartmentalized into dermomyotomes (giving rise to skeletal muscle and parts of the dermis) and sclerotomes (from which bones and ribs are derived). Expression of the paired-box/homeodomain transcription factors Pax3 and Pax 7 marks myogenic stem and progenitor cells within the developing dermomyotome (KassarDuchossoy et al., 2005; Relaix et al., 2005). These Pax3/7-positive cells initiate expression of muscle regulatory factors (MRFs), including Myf5 (myogenic factor 5) Mrf4 (Myf6), MyoD (Myod1, myogenic differentiation 1) and Mef2c (myogenic enhancer factor 2C), which drives progenitors to the muscle lineage (Rudnicki et al., 1993; Edmondson et al., 1994; Kassar-Duchossoy et al., 2004). Subsequently, the muscle progenitors exit the cell cycle, express the transcription factor myogenin and fuse to form multinucleated myotubes (Buckingham and Vincent, 2009). At late fetal stages, Pax3/7-positive cells relocalize to a specific microenvironment adjacent to muscle fibers under the basal lamina (KassarDuchossoy et al., 2005). These cells, which originate from the 
Pax3/7-positive cells of the dermomyotome, persist in a quiescent state in the adult, where they are known as satellite cells and are marked by continued Pax7 expression (Seale et al., 2000) (Schienda et al., 2006) (Fig. 4). Recent studies have shown that Pax7-positive satellite cells exhibit SC properties as they give rise to viable muscles when transplanted into the tibialis anterior muscles of $\mathrm{Pax} 7^{\mathrm{DTR} /-}$ mice (Sambasivan et al., 2011). Moreover, these cells are crucial for muscle regeneration: injury drives quiescent satellite cells back into the cell cycle, inducing myoblast proliferation and differentiation, and hence regeneration of lost muscle fibers. During this process, new satellite cells are formed to replenish the SC pool and ensure muscle cell homeostasis (Sambasivan and Tajbakhsh, 2007; Brack and Rando, 2012). Injured muscle tissue fails to regenerate following ablation of Pax7positive satellite cells, highlighting the role of these cells in muscle regeneration (Sambasivan et al., 2011).

Notch regulates SC maintenance in the developing muscle The early in vitro Notch gain-of-function experiments mentioned above implicated Notch signaling in regulating muscle progenitors.
However, conclusive evidence was obtained only with genetic lossof-function studies. Conditional inactivation of RBP-J in the dermomyotome during embryogenesis leads to an exhaustion of the Pax3/7 muscle progenitor cell pool accompanied by an increase in the MyoD-positive population in the myotome (Vasyutina et al., 2007). This produced a postnatal skeletal muscle deficit (Sambasivan et al., 2011). A strikingly similar phenotype was observed in mice harboring hypomorphic alleles of the Notch ligand Delta-like 1 (Schuster-Gossler et al., 2007). The muscle progenitor cell depletion caused by the loss of Notch signaling can be rescued by genetic ablation of MyoD, although satellite cells in these mice fail to assume the appropriate position between the basal lamina and plasma membrane of myofibers (Bröhl et al., 2012). These data suggest that Notch signaling not only plays a role in maintenance of muscle progenitor cells, but also ensures proper homing of satellite cells to their niche.

Notch signaling is also involved in homeostasis and regeneration in the adult. Using Notch reporter mice combined with gene expression analysis of Notch target genes, the pathway was shown to be active in quiescent satellite cells (Bjornson et al., 2012). Upon

A

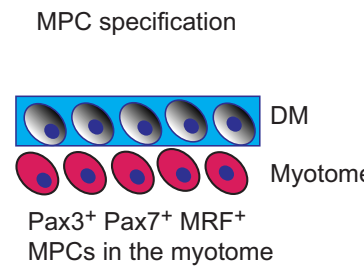

MPCs in the myotome

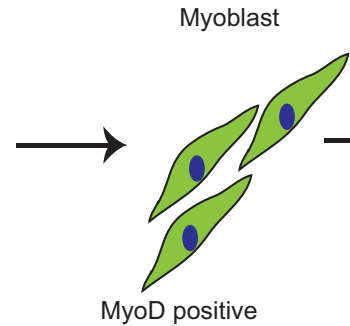

MyoD positive
Fetal myogenesis

Promotes self-renewal and inhibits differentiation

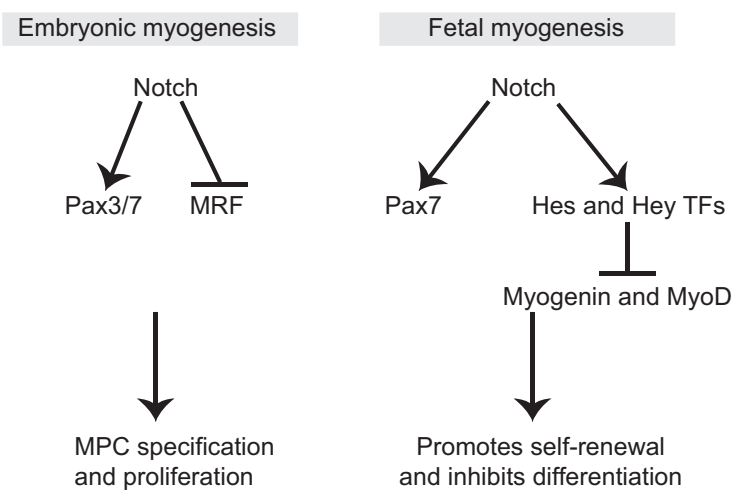

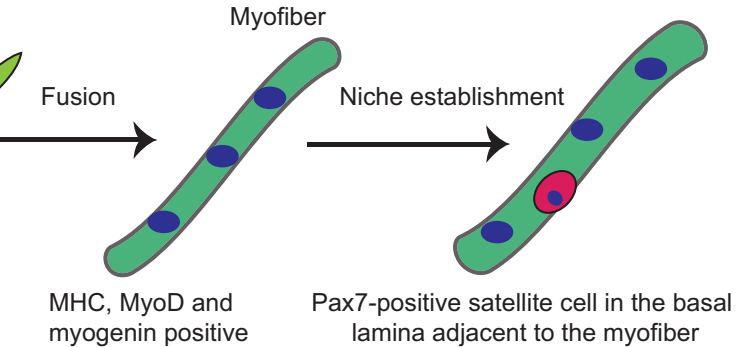

Postnatal myogenesis

Muscle regeneration

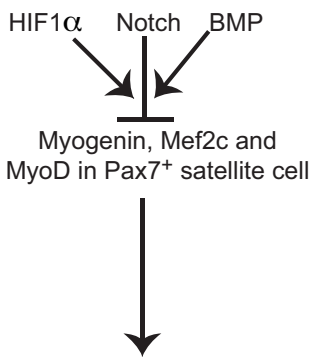

Promotes stem cell maintenance and quiescence

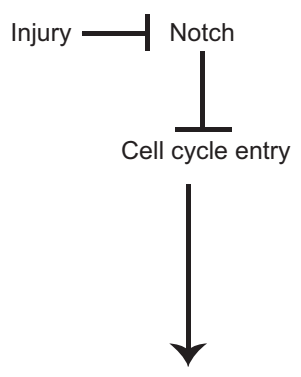

Notch downregulation permits differentiation

Fig. 4. Role of Notch in muscle development and stem cell maintenance. (A) During myogenesis, Pax $3^{+}$Pax $7^{+}$muscle progenitor cells (MPCs) give rise to undifferentiated MyoD-positive myoblasts. Further fusion of myoblasts generates multinucleated myofibers expressing differentiation markers such as myosin heavy chain (MHC), MyoD and myogenin. The basal lamina adjacent to differentiated myofibers acts as a niche for satellite cells during postnatal myogenesis. DM, dermomyotome. (B) Notch signaling contributes to muscle development by regulating the muscle stem/progenitor cells during embryonic, fetal and postnatal myogenesis. During embryonic myogenesis, Notch signaling determines the number of $\mathrm{Pax} 3^{+} \mathrm{Pax} 7^{+}$muscle stem/progenitor cells in the DM and at the same time inhibits lineage commitment by repression of muscle regulatory factors (MRFs), such as Myf5, Mrf4 and MyoD. Pax3 ${ }^{+} P a x 7^{+}$cells in the DM initiate expression of MRFs and form a muscle progenitor cell (MPC)-enriched structure, known as the myotome, adjacent to the DM. During fetal myogenesis, MPCs delaminate from the myotome, migrate to muscle fibers and establish themselves between the basal lamina and plasma membrane of myofibers. In adult myogenesis, these cells are known as satellite cells. During fetal and postnatal myogenesis, Notch-driven transcriptional activation of Pax7 ensures self-renewal of MPCs and satellite cells. In addition to promoting self-renewal of MPCs and satellite cells, activated Notch signaling also inhibits their premature terminal differentiation into skeletal muscle via transcriptional repression of myogenic genes. Notch signaling cooperates with hypoxia inducible factor $1 \alpha$ (HIF1 $\alpha$ ) and bone morphogenetic protein (BMP) signaling to induce expression of Notch target Hes and Hey family of transcriptional factors (TFs). The Hes and Hey family of TFs further repress the transcriptional activation of myogenic genes, thus blocking the terminal differentiation of MPCs and satellite cells. In the course of muscle regeneration, Notch signaling is downregulated, accompanied by an upregulation of Wnt signaling. This allows the satellite cells to exit the quiescence stage and enter cell cycle; activation of myogenic genes such as MyoD, myogenin and MHC further drive their terminal differentiation into multinucleated muscle fibers. 
injury, Notch activity is downregulated, which drives cells out of quiescence. Loss of RBP-J in adult satellite cells negatively affects muscle regeneration owing to premature differentiation and hence depletion of satellite cells. Interestingly, most of these cells differentiated without cell cycle entry (Bjornson et al., 2012; Mourikis et al., 2012) (Fig. 4). The importance of Notch signaling in satellite cell maintenance was further shown in aged animals, which exhibit a loss of Notch signaling in muscle cells, thus depleting the satellite cell pool required for muscle regeneration. Ectopic expression of Notch in aged muscle restores the regenerative potential of satellite cells (Conboy et al., 2003). Thus, in muscle, as in the nervous system, Notch signaling is crucial for the maintenance of self-renewing progenitor cells during development, as well as in the adult.

\section{Mechanistic insights into Notch function in the adult muscle}

How Notch signaling restores the regenerative potential of aged muscle cells or how it inhibits differentiation of muscle stem and/or progenitor cells is unclear. However, data suggest that Notch might regulate self-renewal of satellite cells through direct transcriptional regulation of $\operatorname{Pax} 7$ (Wen et al., 2012): NICD and RBP-J have been shown to bind RBP-J consensus sites within the promoter region of Pax7 (Wen et al., 2012). Constitutive activation of Notch signaling in satellite cells promotes their self-renewal via upregulation of $\operatorname{Pax} 7$, and maintains them in an undifferentiated stage by transcriptional repression of MyoD and myogenin via the Hes and Hey family of transcriptional repressors (Wen et al., 2012). Earlier studies suggested that NICD could directly interact with Mef2c, blocking its transcriptional potential to activate myogenic genes (Wilson-Rawls et al., 1999). Similarly, the Notch target Heyl transcriptionally represses key myogenic genes, including myogenin and Mef2c, preventing differentiation of muscle progenitors into multinucleated myotubes (Buas et al., 2010).

Notch signaling also influences myogenesis through cooperation with other signaling pathways. Bone morphogenetic protein (BMP) signaling induces proliferation of satellite cells and plays a role in blocking their premature differentiation (Ono et al., 2011). In this context, BMP4/SMAD1 signaling promotes Notch-dependent activation of Hes1 and Hey1 to inhibit differentiation of satellite cells and C2C12 myoblasts (Dahlqvist et al., 2003). In addition, hypoxic conditions block muscle differentiation and promote an undifferentiated cell state through direct interaction of hypoxiainducible factor $1 \alpha(\mathrm{HIF} 1 \alpha)$ with NICD, resulting Hes 1 and Hey2 expression (Gustafsson et al., 2005).

Finally, crosstalk between Notch and Wnt signaling in satellite cells seems to regulate the transition from an undifferentiated to a differentiated state during postnatal myogenesis. In satellite cells with high Notch and low Wnt signaling, glycogen synthase kinase $3 \beta$ (GSK3 $\beta$ ) facilitates a switch to low Notch and high Wnt activity, which then drives muscle differentiation. Inhibition of Notch signaling in regenerating muscle leads to upregulation of Wnt pathway activity and premature muscle differentiation. Therefore, the temporal crosstalk between Notch and Wnt is part of a mechanism that ensures proper proliferative expansion followed by differentiation to allow correct myogenesis (Brack et al., 2008). The exact molecular mechanism regulating the inhibition and activation of Notch and Wnt, respectively, through GSK3 $\beta$, needs further investigation (Brack et al., 2008) (Fig. 4).

In summary, Notch signaling plays a crucial role in the maintenance and self-renewal of muscle SCs in the embryo and adult. Whether the interplay between Notch and other signaling cascades can be exploited for therapeutic intervention in muscle degenerative diseases remains to be seen.

\section{Notch regulates differentiation in the Drosophila intestine}

The posterior midgut in Drosophila is a well-established model system for studying intestinal SC biology. Intestinal SCs (ISCs) in the midgut divide asymmetrically to give rise to an intermediate cell type called the enteroblast (EB). EBs further differentiate into either an enterocyte (EC) or an enteroendocrine (EE) cell. EE cells are marked by the expression of the transcription factor Prospero, while ECs can be identified by the expression of $P d m 1(\mathrm{Nub})$ and their ability to undergo endoreplication. ISCs have also been shown to undergo symmetric cell division, giving rise to either two ISCs or two committed cells (Micchelli and Perrimon, 2006; Ohlstein and Spradling, 2006; de Navascués et al., 2012).

Micchelli and Perrimon identified ISCs as escargot-positive cells that express the Notch ligand Delta (Micchelli and Perrimon, 2006). By contrast, EBs express the Notch receptor, receiving signals from the Delta-positive ISCs (Micchelli and Perrimon, 2006) (Fig. 5A). Notch signaling in the Drosophila midgut has been proposed to regulate SC maintenance, differentiation and proliferation in coordination with various signaling pathways. The interaction of the Hairless and $\mathrm{Su}(\mathrm{H})$ complexes primarily dictates self-renewal versus differentiation of ISCs: Hairless-mediated repression of $\mathrm{Su}(\mathrm{H})$ in ISCs leads to a downregulation of the Notch target gene Enhancer of split, thus maintaining the self-renewal properties of ISCs (Bardin et al., 2010). Notch activation also regulates the proliferative index of ISCs. Functionally, loss of Notch signaling in temperature-sensitive Drosophila strains (harboring mutations in the Notch locus) causes an expansion of escargot ${ }^{+}$ISCs, whereas Notch overactivation leads to decreased proliferation of ISCs (Micchelli and Perrimon, 2006).

Genetic loss- or gain-of-function studies in Drosophila also suggest that Notch signaling in EBs plays an active role in lineage commitment and terminal differentiation into the EC population (Micchelli and Perrimon, 2006; Ohlstein and Spradling, 2006; Ohlstein and Spradling, 2007; Takashima et al., 2011). In Drosophila midgut, the strength of Notch signaling, facilitated by post-translational modification of the receptor by GDP-mannose 4,6-dehydratase (GMD) and O-fucosyltransferase 1, differentially regulates lineage commitment versus terminal differentiation of ISCs (Perdigoto et al., 2011). GMD and O-fucosyltransferase 1 promote a higher level of Notch activation, which is required for lineage commitment of ISCs, whereas low levels of Notch signaling are sufficient to induce terminal differentiation in EBs (Perdigoto et al., 2011).

In addition to the Notch pathway, several others are implicated in regulating ISC proliferation, including EGFR, Wnt and JAKSTAT (Biteau and Jasper, 2011; Xu et al., 2011). One of the potential mechanisms by which Notch negatively regulates ISC proliferation is by antagonizing JAK-STAT signaling (Bertrand et al., 2010). JAK-STAT activity in ISCs is required for cell cycle entry from quiescence. Notch signaling has been proposed to inhibit transcription of the JAK-STAT ligand gene unpaired, thereby blocking pathway activation. This leads to a block in proliferation of ISCs (Liu et al., 2010b). Moreover, Notch signaling has also been shown to keep a check on stress-induced proliferation of ISCs by inhibiting Jun N-terminal kinase (JNK) signaling in aging flies (Biteau et al., 2008).

In summary, Delta-mediated Notch signaling between ISCs and EBs plays a crucial role in homeostasis of the midgut in the fly. In 
A Absorptive cells:
enterocyte (EC)

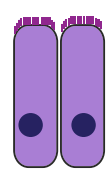

Secretory cells: enteroendocrine (EE) cell

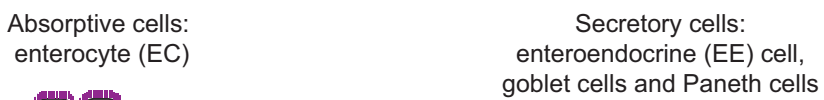

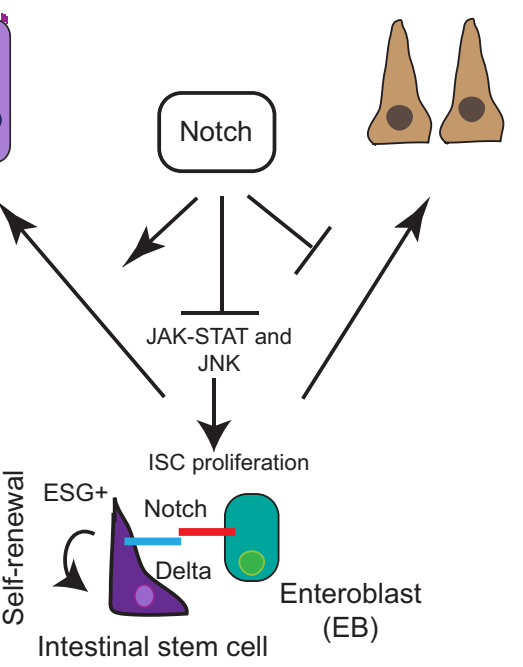

(ISC)

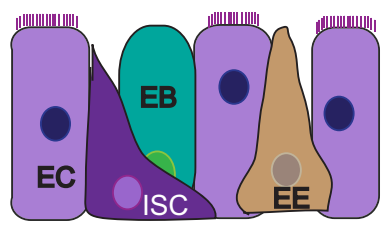

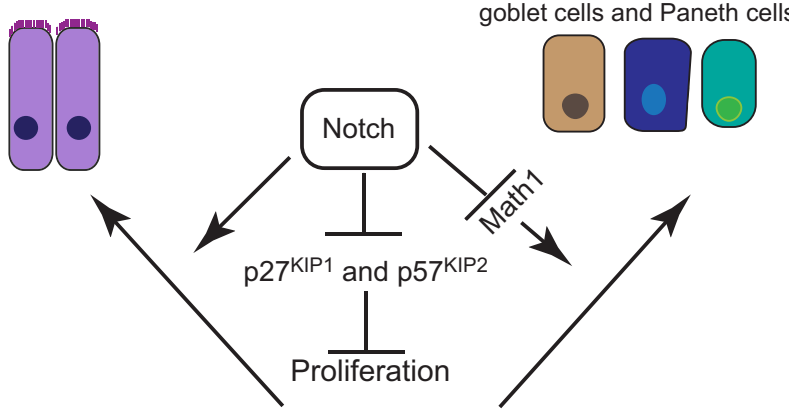
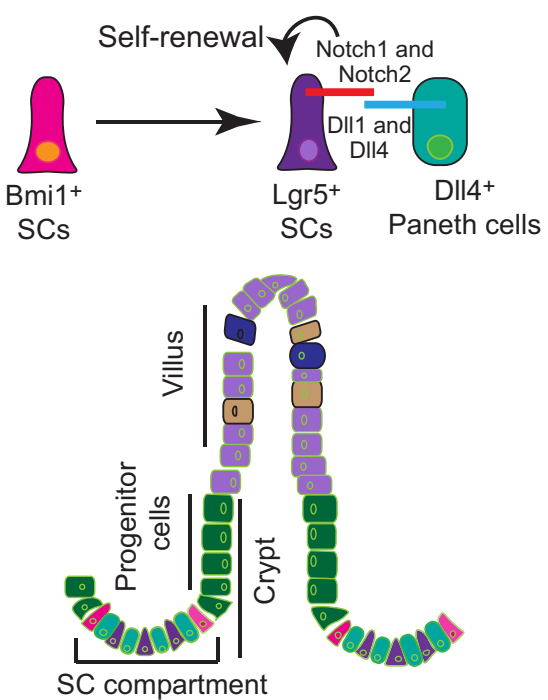

Fig. 5. Notch function in the Drosophila and murine intestine. (A) In the Drosophila midgut, intestinal stem cells (ISCs) (escargot ${ }^{+}$) reside between a monolayer of enteroblasts (EBs), enteroendocrine (EE) cells and enterocytes (ECs). ISCs express the Notch ligand Delta and send a signal to the Notch receptor expressing EBs. Strong Notch signaling in EBs favors the EC cell fate. Activated Notch signaling in EBs also blocks proliferation of ISCs by antagonizing the JAK-STAT and JNK pathways under physiological and stress conditions. (B) Role of Notch in mouse ISCs: long-lived Bmi $1^{+}$SCs reside at the +4 position in the crypt compartment and give rise to mitotically active Lgr5 ${ }^{+}$SCs. In the crypt compartment, Notchexpressing $\mathrm{Lgr5}^{+} \mathrm{SC}$ are sandwiched between Delta-like $4^{+}$Paneth cells. Activation of Notch signaling in Lgr5 ${ }^{+}$cells maintains SC self-renewal and proliferation by negative regulation of the cyclin-dependent kinase inhibitors p2 $7^{\mathrm{KIP} 1}$ and $\mathrm{p} 57^{\mathrm{KIP} 2}$, and the transcription factor Math1, which is necessary for differentiation of the secretory cell lineages. Notch thus biases cell fate choice towards the absorptive lineage.

Drosophila, Notch pathway activation dictates symmetrical division of ISCs and controls their proliferation via the JAK-STAT and JNK pathway. In addition, the levels of Notch signaling also determine cell fate decisions in ISCs, thus maintaining the appropriate numbers of EC and EE cells in the Drosophila intestine.

\section{Notch - a stem and progenitor gatekeeper in the murine intestine}

In contrast to the Drosophila midgut ISCs, mouse ISCs give rise to ECs and three secretory cell lineages [goblet cells, Paneth cells (PCs) and EE cells] (Fre et al., 2009), and homeostasis in the small intestine appears to be maintained by distinct populations of SCs. Whereas the precise nature of these different populations, and the relationships between them, are not fully understood, current data suggest the existence of a long-lived pool of SCs marked by the Polycomb group protein Bmil, and a mitotically active pool marked by Lgr5 (Barker et al., 2007; Sangiorgi and Capecchi, 2008). Data from clonogenic spheroid cultures suggest that the $\mathrm{Lgr}^{+}$pool of SCs arise from Bmil $1^{+}$cells in the intestine (Barker et al., 2007; Sangiorgi and Capecchi, 2008; Yan et al., 2012). In fact, $\mathrm{Bmil}^{+}$cells can compensate for ablation of the $\mathrm{Lgr}^{+}$cell population, thereby maintaining intestinal homeostasis (Tian et al., 2011). Recent studies have also identified a third subset of ISCs. This population is non-cycling and is marked by LRIG expression (Powell et al., 2012; Wong et al., 2012). However, whether LRIG1 ${ }^{+}$ ISCs give rise to different cell types in the intestine via or independently of the $\mathrm{Lgr}^{+}$cell population needs to be established by lineage-tracing experiments.

$\mathrm{Lgr}^{+}$stem/progenitor cells retain the ability to give rise to all lineages of the intestinal epithelium (Sato et al., 2009). At the bottom of the crypt, each $\operatorname{Lgr} 5^{+}$stem/progenitor cell is sandwiched between PCs. These serve as a niche for $\mathrm{Lgr}^{+}$stem/progenitor cells, providing them with important signaling cues required for maintaining intestinal homeostasis. PCs express the Notch ligand Delta-like 4 and several mitogenic factors, including Wnt3, Wnt11, transforming growth factor $\beta$ and EGF (Sato et al., 2011), which help to maintain proliferation in neighboring $\operatorname{Lgr} 5^{+}$stem/progenitor cells (Fig. 5B).

Notch and Wnt signaling play crucial roles in coordinating proliferation and differentiation of ISCs in the intestine. Canonical 
Wnt signaling via transcription factor 4 has been shown to regulate ISCs in the crypt compartment of the intestine (Korinek et al., 1998). In addition to its role in the maintenance of ISCs, the Wnt pathway also promotes differentiation of the secretory cell lineage in the intestine (Pinto et al., 2003). Whether there is a direct crosstalk between Notch and Wnt signaling in the intestine under physiological conditions is not clear, but Notch signaling also plays an important role in the maintenance of ISCs as well as their commitment towards the absorptive lineage. Pharmacological inhibition of the Notch pathway using $\gamma$-secretase inhibitors skews differentiation towards the secretory cell fate (goblet cells) (Milano et al., 2004). Similarly, intestine-specific inactivation of RBP-J results in the conversion of proliferative crypt progenitor cells into post-mitotic goblet cells. These results demonstrated that RBP-Jmediated Notch signaling is essential for the maintenance of crypt progenitors (van Es et al., 2005), and for the regulation of cell fate. However, activation of Notch signaling leads to amplification of the intestinal stem/progenitor pool, accompanied by a block in differentiation of secretory cells (Fre et al., 2005). Definitive evidence for Notch activity in ISCs came from lineage-tracing experiments using specific reporter mice to follow the progeny of ISCs that received a Notch1 signal. Eight months after Notch activation, entire crypt villi were still labeled, demonstrating that the Notch pathway is active in SCs that give rise to all progeny in the intestine (Pellegrinet et al., 2011). The expression and activation of Notch1 and Notch2 in ISCs was further confirmed by independent studies using Notch1/2-CreERT2:R26 lacZ reporter strains (Fre et al., 2011). Activation of Notch signaling in mouse ISCs is in stark contrast to Drosophila, in which Notch is active in EBs, but not in ISCs (Fig. 5A). As is the case for SCs in the muscle, Notch signaling in the mouse intestine is essential for the $\mathrm{SC}$ maintenance.

Genetic studies revealed the nature of the ligands and receptors responsible for maintenance of the SC compartment in the mouse intestine. Simultaneous ablation of both Notch1 and Notch 2 in the intestine phenocopies RBP-J loss of function, namely goblet cell metaplasia and loss of proliferative stem/progenitors cells (Riccio et al., 2008). Mechanistically, Notch signaling maintains the proliferative crypt compartment via Hes1-mediated repression of the cyclin-dependent kinase (CDK) inhibitors p $27^{\mathrm{Kip} 1}$ and p5 $7^{\mathrm{Kip} 2}$ (Cdkn1b and Cdkn1c) (Riccio et al., 2008). Simultaneous inactivation of Hes1, Hes3 and Hes5 in the small and large intestine leads to an accumulation of secretory cells and to a decrease in proliferation within the crypt compartment (Ueo et al., 2012). Similarly, in vivo studies identified Delta-like 1 and Delta-like 4 as physiological ligands for Notch receptors in this context. Intestinalspecific deletion of Delta-like 1 and Delta-like 4 triggers loss of the SC compartment, as demonstrated by loss of the SC markers Lgr5, olfactomedin 4 (Olfm4) and Ascl2 (Pellegrinet et al., 2011). Furthermore, Notch inhibition by $\gamma$-secretase inhibitors or antibodies against Notch1/Notch2 causes downregulation of Olfm 4 in the intestine, identifying Olfm 4 as a direct target of the pathway (VanDussen et al., 2012).

In addition to its role in regulating proliferation and self-renewal - executed via Hes-mediated repression of CDK inhibitors - there appears to be a second independent function for Notch in controlling cell fate. As mentioned above, loss of Notch promotes goblet cell differentiation. The inhibitory effect of Notch on secretory cell differentiation appears to be mediated by negative regulation of mouse atonal homolog 1 (Math1; Atoh1). Math1 promotes the secretory cell fate commitment from progenitor cells (Fig. 5B): loss of Math1 in the intestine leads to loss of the secretory cell population, whereas gain-of-function causes an accumulation of secretory cells at the expense of the absorptive EC lineage (Yang et al., 2001; VanDussen and Samuelson, 2010). Active Notch signaling in stem/progenitor cells of the intestine favors the absorptive over the secretory cell fate (Ueo et al., 2012), and the accumulation of secretory cells observed in the absence of Notch signaling can be rescued by depletion of Math1. Furthermore, Math1 has also been shown to regulate proliferation in the crypt compartment, as loss of Math1 on a Notch-deficient background re-establishes Hes1 expression, thus restoring proliferation in the crypt compartment (Kim and Shivdasani, 2011).

In light of recent advances in the field of intestinal SC biology, it is clear that the Notch pathway plays important roles in diverse but strikingly similar ways in the intestinal tissue of mouse and Drosophila. In the Drosophila midgut, ISCs present Delta ligand to activate Notch signaling in the receptor-expressing EB cells, while in mouse intestine, SCs express the Notch1 and Notch2 receptors, thus acting as a signal-receiving cells, with the neighboring PCs providing the ligand source. Thus, although Notch is activated in different cell types in Drosophila midgut and mouse intestine, it regulates SC maintenance, proliferation and lineage commitment in both species.

\section{Notch signaling in hematopoietic SC ontogeny - parallels in fish and mice \\ Sites of embryonic hematopoietic SC development}

Embryonic hematopoietic development in vertebrates can be divided into two distinct phases: primitive and definitive hematopoiesis. In mice, primitive hematopoiesis occurs in an extra-embryonic site, the yolk sac, whereas, in zebrafish, the primitive wave is initiated in two intraembryonic sites - the anterior and the posterior lateral mesoderm. During primitive hematopoiesis in both species, transient populations of progenitors give rise to erythrocytes and macrophages (de Jong and Zon, 2005; Cumano and Godin, 2007). During the second phase of definitive hematopoiesis, which originates mostly from the aorta-gonad-mesonephros (AGM) region, as well as the placenta in mammals and the ventral wall of the dorsal aorta (DA) in zebrafish, definitive hematopoietic SCs (HSCs) are generated. These cells give rise to the full range of blood cells in the embryo and throughout adulthood.

Elegant studies in zebrafish and the mouse embryo showed that a subset of endothelial cells move out from the ventral wall of the DA into the sub-aortic space and transform into presumptive HSCs by a process termed endothelial hematopoietic transition (Bertrand et al., 2010; Boisset et al., 2010; Kissa and Herbomel, 2010; Lam et al., 2010). Using fluorescent reporter transgenes in zebrafish embryos, Bertrand et al. visualized and identified the stepwise intermediates as aortic hemogenic endothelium transitions, giving rise to nascent HSCs (Bertrand et al., 2010) in the sub-aortic space. From there, the newly generated HSCs enter the circulation and home either to the thymus or to the pronephros kidney to allow for expansion and development. Boisset et al. showed in the mouse embryo that de novo definitive HSCs arise directly from ventral aortic endothelial cells, which shed into the lumen of the DA (Boisset et al., 2010). HSCs then enter the circulation and home to the fetal liver for expansion and differentiation.

During these successive hematopoietic processes, many different signaling pathways, such as Notch, Wnt, Hedgehog, VEGF, Bmp and FGF have been demonstrated to be crucial for different stages of HSC development. Below, we focus on the role of Notch signaling during embryonic, as well as adult, HSC development and maintenance, bridging data from fish and mice. 


\section{Notch - a driving force in definitive hematopoiesis}

Several studies have revealed the importance of Notch signaling for vascular morphogenesis and arterial specification (Box 3). As hemogenic endothelium in the DA is the key site for definitive hematopoiesis where HSCs first emerge in vertebrates, it is important to address whether failure of arterial specification hampers HSC emergence. Here, we discuss the effects of Notch signaling on HSC specification and whether they are independently regulated from vascular development and arterial versus venous fate specification.

The initial connection between definitive hematopoiesis and a role for Notch signaling was made by Kumano et al., who showed in mouse that Notch1 is essential for generating hematopoietic cells from endothelial cells in the AGM (Kumano et al., 2003). By contrast, they found that loss of Notch had no effect on primitive hematopoietic progenitors generated in the yolk sac. A study using blastocyst chimeras to discriminate between cell-autonomous and non-cell-autonomous effects of Notch signaling revealed that Notch1 is required in a cell-autonomous manner for the establishment of long-term definitive HSCs (Hadland et al., 2004). The essential role of Notch signaling in the generation of HSCs was also confirmed using RBP-J-deficient animals (Robert-Moreno et al., 2005), and mice with a conditional ablation of mindbomb 1 (Yoon et al., 2008b). Although these embryos are deficient in AGM-derived HSCs, they contain primitive progenitors in the yolk sac.

Although these loss-of-function studies suggested an important role for Notch in the generation of HSCs during embryonic development, this could simply be a consequence of impaired arterial cell fate specification and vasculogenesis. This uncertainty was resolved by showing that Jag1-, but not Jag2-null embryos failed to generate hematopoietic progenitors within the AGM region, but importantly maintained the arterial cell fate (RobertMoreno et al., 2008). Therefore, Notch is directly associated with the generation of $\mathrm{HSCs}$, independently of its role during vasculogenesis.

The list of molecular downstream targets of Notch signaling implicated in HSC generation during definitive hematopoiesis is not extensive. This is mostly due to the inability to distinguish between Notch targets required to induce arterial specification and those required for HSC generation. Runx1 (Runt-related transcription factor 1), a transcription factor that is essential for HSC emergence during the endothelial to hematopoietic cell fate conversion, but not thereafter (Chen et al., 2009), functions together with CREB-binding protein $\beta$ and is a proposed downstream target of Notch signaling (Burns et al., 2005). However, direct regulation of Runx1 through Notch has yet to be shown. Nevertheless, the finding that Runx 1 is downregulated in Notch1 and Rbpj mutant embryos, and, more importantly, that retroviral overexpression of Runx1 in Notch-deficient prehematopoietic precursor cells is sufficient to rescue hematopoietic potential, indicated that Runx1 is a key factor in Notch1-RBP-J-mediated mammalian hematopoiesis (Nakagawa et al., 2006).

Studies in zebrafish have also confirmed that Runx1 expression is dependent on Notch and promotes HSC expansion (Burns et al., 2005). Furthermore, the Hey2 homolog gridlock not only functions in arterial specification (Box 3) but also plays a role in HSC formation, as gridlock-deficient zebrafish embryos displayed reduced expression of Runx1 (Rowlinson and Gering, 2010). Chromatin immunoprecipitation assays have revealed that Notch1 is directly recruited to the gata 2 promoter (Robert-Moreno et al.,
Box 3. Notch signaling during vascular development artery specification

Studies in zebrafish already indicate a crucial role for Notch activity not only in embryonic hematopoietic stem cell (HSC) development, but also in vascular/angiogenic development. Given that arterial specification can be viewed as an important prerequisite for HSC emergence (Bertrand et al., 2010; Boisset et al., 2010; Kissa and Herbomel, 2010), Notch activity in the vascular system may also have an impact on hematopoiesis. A novel Notch signaling activity in zebrafish was shown to modulate fate specification of endothelial progenitors in the mesoderm, such that inhibition of Notch activity at an early stage promoted endothelial cell production at the expense of hematopoietic lineages (Lee et al., 2009). Moreover, genetic analysis has revealed a crucial role for Notch activity in mammalian vascular morphogenesis and artery specification (Krebs et al., 2000): both Notch1-deficient mouse embryos and compound-deficient embryos lacking Notch1 and Notch4 have severe vascular defects and die in utero prior to embryonic day 10.5. These findings have been recapitulated with specific conditional inactivation of Notch1 in endothelium (Limbourg et al., 2005). Both studies highlight the essential role of Notch signaling in the endothelium during vascular development and indicate a cellautonomous function. Targeted deletion of several other players in the Notch signaling pathway, such as RPB-J (Krebs et al., 2004), mindbomb 1 (Koo et al., 2005), or Hey1 and Hey2 (Fischer et al., 2004), as well as Delta-like 4 (Duarte et al., 2004) were also shown to be essential for arterial specification. Moreover, the Notchgridlock (Hey2 in mice) signaling axis regulates arterial versus venous cell fate choice in zebrafish. Gridlock, which is normally considered to be downstream of Notch signaling, was recently shown to act upstream of Notch in this context: overexpression of the Notch intracellular domain in gridlock mutants rescues the arterial phenotype (Rowlinson and Gering, 2010).

2005). Interestingly, abrogation of Notch signaling and concomitant loss of Gata2 expression led to decreased Runx 1 expression. Gata2 is involved in the regulation of Runx1 expression (Nottingham et al., 2007), providing a mechanistic explanation for the regulation of Runx 1 expression by Notch (Fig. 6).

The identity of the ligands that mediate Notch signaling in the AGM is incompletely understood. Jag1 but not Jag2 is essential for the emergence of normal numbers of definitive HSCs from the AGM (Robert-Moreno et al., 2008). However, other Notch ligands, such as Delta-like 1 and Delta-like 4 are also expressed in the AGM region (Robert-Moreno et al., 2008; Yoon et al., 2008b). Conditional ablation approaches will be required to ascertain whether these ligands play a specific role here.

An interesting observation made in zebrafish links non-canonical Wnt signaling with the Notch cascade to specify HSCs non-cellautonomously (Clements et al., 2011). Wnt16, which is expressed in somites, controls the emergence of HSCs by regulating somitic expression of the Notch ligands DeltaC and DeltaD, which are required for arteriovenous and HSC specification. However, loss of Wnt16 resulted only in an HSC defect, rather than vascular abnormality. Thus, the Wnt16-Delta-Notch pathway seems to act separately from the traditional Hedgehog-VEGF-Notch cascade in controlling artery-vein specification and emergence of HSCs.

\section{Notch signaling in adult vertebrate HSCs - a controversy resolved}

Although the studies discussed above have now clearly defined a role for Notch signaling in embryonic HSC development, the 


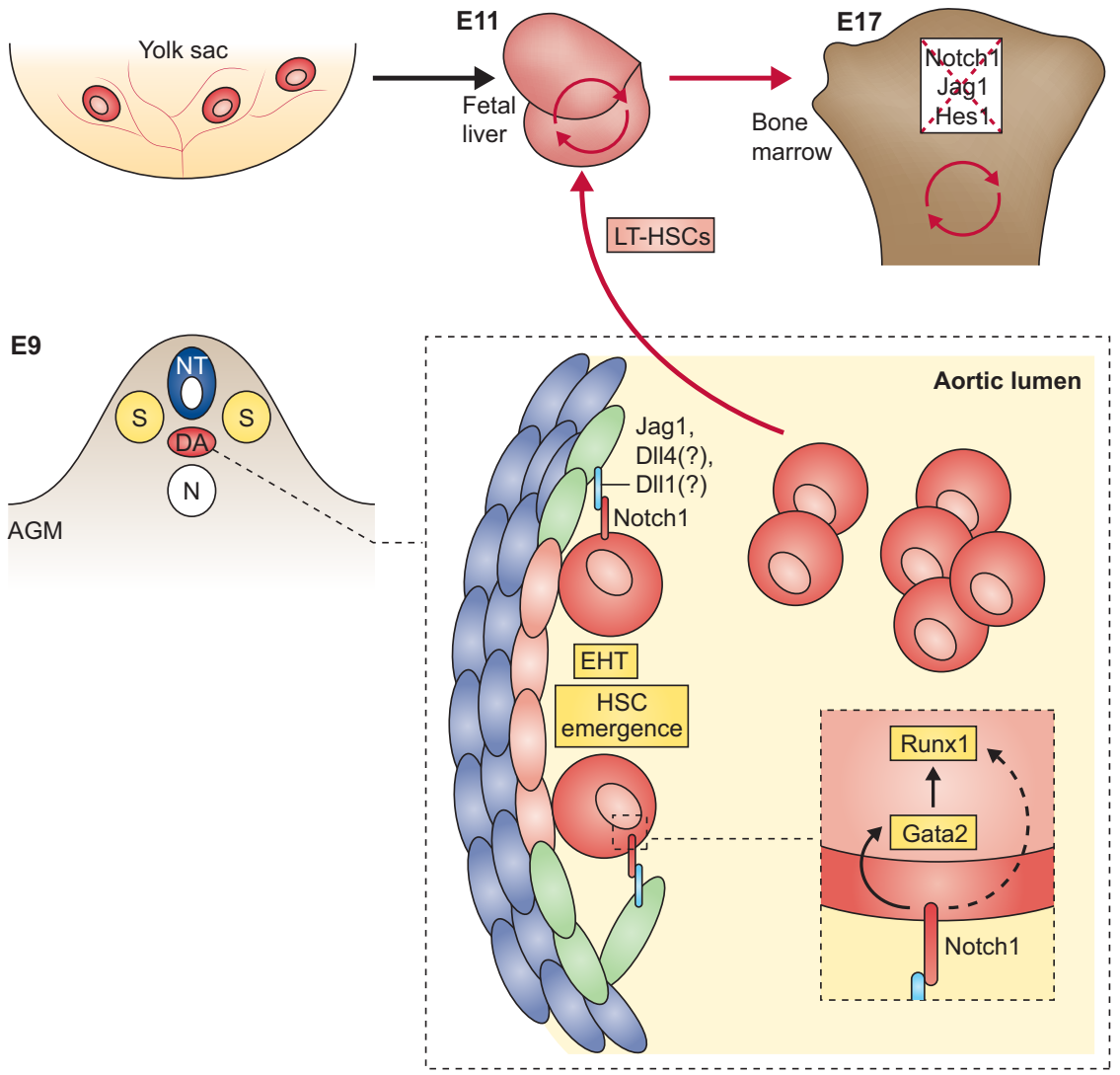

Fig. 6. Notch signaling drives hematopoietic stem cell specification during development. Notch signaling drives cell-autonomous hematopoietic stem cell (HSC) specification in the dorsal aorta (DA). The DA in the aorta-gonad-mesonephros (AGM) region at embryonic day 9 (E9) is shown. In the enlargement, surrounding mesenchymal cells of the DA are shown in blue, aortic endothelial cells are in green and hemogenic endothelial cells are in light red, transitioning to HSCs in red. During vertebrate embryonic development, aortic endothelial cells of the DA express Jagged 1 (Jag1), Delta-like 1 and Delta-like 4 ligands, whereas cells destined to emerge as HSCs express the Notch 1 receptor. Interaction between Jag1 and Notch1 is essential for HSC specification. Newly generated HSCs emerge via endothelial-to-hematopoietic transition (EHT) and shed into the aortic lumen. From there, the long-term HSCs (LT-HSCs) will seed the fetal liver at E11 and proceed to self-renew. The final prenatal destination (E17) is the bone marrow. Notch signaling is dispensable for HSC

maintenance in the bone marrow - depicted as crossed-out ligands, receptors and targets. Prior to definite hematopoiesis, the yolk sac also gives rise to a wave of primitive hematopoiesis. Red circular arrows indicate HSC self-renewal. $\mathrm{N}$, notochord; NT, neural tube; S, somite. requirement for Notch signaling in generating adult HSCs has remained controversial for many years. The Notch1 receptor was first identified in human hematopoietic cells through its involvement in a chromosomal translocation found in a small cohort of children with T-cell acute lymphoblastic leukemia (TALL) (Ellisen et al., 1991). Subsequently, Milner et al. demonstrated that Notch is expressed in undifferentiated progenitors from human bone marrow (BM) cells (Milner et al., 1994). Notch signaling has since been shown to be essential for several hematopoietic differentiation processes. For example, the $\mathrm{T}$ - versus B-cell fate specification in the thymus is mediated through a Notch1/Delta-like 4 interaction, and the emergence of marginal zone B cells is dependent upon a Notch2/Delta-like 1 interaction (reviewed by Radtke et al., 2010). However, the role of Notch signaling in adult vertebrate HSC maintenance remained controversial, largely because gain- and loss-of-function studies have not produced consistent results.

Multiple gain-of-function studies have suggested that Notch signaling could expand undifferentiated hematopoietic progenitors, including HSCs. Addition of soluble human JAG1 to ex vivo cultures of purified human cord blood cells (Karanu et al., 2000) or the in vitro culture of $\mathrm{Lin}^{-} \mathrm{CD} 117^{+} \mathrm{Sca}^{+}(\mathrm{KLS})$ mouse $\mathrm{BM}$ cells in combination with an immobilized engineered DL1 ${ }^{\text {ext-IgG }}$ ligand plus growth factors promote in vitro expansion of these progenitor populations (Varnum-Finney et al., 2003). Subsequent transplantation assays of either cell population into NOD/SCID mice revealed their short-term reconstitution potential. However, serial transplantability to ensure long-term SC potential was not evaluated. Jag1-mediated Notch1 signaling has been implicated in the expansion of long-term HSCs. Transgenic overexpression of an activated parathyroid-hormone (Pth/Pthlh) mutant receptor in osteoblasts led to the upregulation of Jag1 and to a concomitant increase of NICD in HSCs. The resultant Notch-mediated HSC expansion could be blocked in vitro by $\gamma$-secretase inhibitors (Calvi et al., 2003). Nevertheless, it should be noted that constitutive activation of $\mathrm{Pth} / \mathrm{Pthlh}$ in osteoblasts could initiate HSC expansion in different, Notch-independent, ways. Pth itself has a tremendous impact on bone remodeling and induces secretion of several growth factors, such as BMPs and insulin-like growth factor 1, which could also influence HSC homeostasis (Whitfield et al., 2002; Hadjidakis and Androulakis, 2006). Moreover, additional trabecular bony structures and increased osteoblasts were observed in these mice, a phenotype that is also observed in BMP receptor 1A-deficient animals that show a twofold increase in the number of long-term HSCs. These data further support a tight connection between Pth activation and BMP release (Zhang et al., 2003), and thus alternative mechanisms to expand HSCs.

In other gain-of-function approaches, both in vivo and in vitro, it has been shown that constitutive overexpression of NICD preserved and/or expanded hematopoietic progenitors (VarnumFinney et al., 2000; Stier et al., 2002). In addition, a distinct role for Notch2 in modulating progenitor growth and differentiation was shown in ex vivo cultures using either Jag1 or Delta-like to activate Notch2 in HSCs, which blocked myeloid differentiation and enhanced the generation of multipotent progenitors (Varnum-Finney et al., 2011). Immortalized endothelial cells expressing the Notch ligands Jag1, Jag2, Delta-like 1 and Deltalike 4 supported Notch-mediated expansion of a long-term HSC fraction, and permitted their long-term reconstitution in lethally irradiated mice (Butler et al., 2010), though only if signaling through both Notch1 and Notch2 receptors occurred. Taken together, these approaches revealed a significant impact of increased Notch signaling on HSCs, resulting in substantial in vitro expansion of progenitors. 
A promising modified approach is now being used in a clinical phase 1 myeloablative cord blood transplantation trial. Ex vivo expansion cultures of $\mathrm{CD} 4^{+}$cord blood progenitors in the presence of Notch ligands show a more than 100-fold increase in $\mathrm{CD} 34^{+}$cells, which efficiently repopulate immunocompromised NOD.SCID IL-2 receptor $\gamma$ chain knockout (NSG) mice (Delaney et al., 2010). This method could provide a powerful therapeutic approach in light of the limited numbers of HSCs available, as it would facilitate and expedite hematopoietic reconstitution. Although this evidence shows that Notch signaling plays an important role in the expansion and proliferation of multipotent progenitors, it does not unambiguously prove that Notch signaling is essential for HSCs subsequent to their emergence in the early and postnatal embryo.

In contrast to the wealth of supportive data obtained by Notch gain-of-function analysis, several genetic studies using loss-offunction approaches have not identified an essential role for Notch signaling in adult HSCs. Conditional deletion of either Jagl, Notch1, Notch1 and Notch2 together, or Rbpj in adult HSCs show no effect on HSC maintenance or proliferation (Radtke et al., 1999; Mancini et al., 2005; Maillard et al., 2008). Similarly, combinatorial deletion of $\mathrm{Jag} 1 \mathrm{in}$ BM stromal cells and inactivation of Notch1 in HSCs revealed no effect on HSC maintenance, therefore excluding an essential contribution of Jag1-mediated Notch1 signaling for adult HSC self-renewal (Mancini et al., 2005). However, these studies did not address the redundancy that could result from expression of other Notch receptors or ligands in hematopoietic tissues. This issue was subsequently addressed using genetic approaches inhibiting all canonical Notch signals in adult HSCs by conditional ablation of Rbpj, and in parallel experiments where a dominant-negative (dn) MAML1 retroviral construct (Maillard et al., 2008) was expressed in HSCs. Neither RBPJdeficient nor dnMAML1-expressing HSCs showed any HSC defects in stringent SC assays (Maillard et al., 2008). Although Notch1, Notch2 and Hes1 are expressed in HSCs, albeit at low transcript levels (Maillard et al., 2008), a physiological role for the transcriptional Notch target Hes 1 has not been established in HSCs (Wendorff et al., 2010). Consequently, these results provide conclusive evidence that Notch signaling does not play an obligate physiological role in adult HSC homeostasis under steady-state conditions or in competitive and stress situations. Nevertheless, although Notch signaling is dispensable in adult HSCs, the studies showing that HSCs can be successfully expanded by Notch activation in vitro may still prove useful, particularly for clinical purposes (Fig. 6).

\section{Conclusions}

The role of Notch signaling in SCs has been the focus of many scientists from different disciplines. Interplay between Notch ligands and receptors influences stem and progenitor cell maintenance, lineage specification mediated through either binary cell fate decisions or lateral inhibition, and induction of terminal differentiation (Dumortier et al., 2005). Drosophila, zebrafish and murine SCs of the embryonic and adult nervous systems have been shown to require Notch signaling to preserve the neuronal stem/progenitor pool. As neurogenic Notch mutations in Drosophila also caused muscle defects, Notch signaling was implicated in regulation of myogenesis (Poulson, 1937; Bate et al., 1993). It was also recently shown that Notch acts as a SC gatekeeper in muscle progenitors during development and adulthood. How Notch signaling restores the regenerative potential of aged muscle cells or how it inhibits differentiation of muscle
SCs remains unknown. In intestinal SC biology, the Notch pathway plays an important role in mice and flies. Whereas Notch signaling is necessary for SC maintenance in mice, it is only important for proper differentiation of intestinal progenitor cells in Drosophila. An interesting exception is seen in the vertebrate hematopoietic system where Notch signaling is essential for embryonic HSC development but dispensable for adult HSCs. These findings are summarized and compared in detail in Table 2. Efforts that merge genetic approaches, cell culture and pre-clinical model systems advance and strengthen our current understanding of Notch signaling in SCs. How this can be exploited for therapeutic interventions in disease remains to be seen.

\section{Acknowledgements}

We thank Dr Anne Wilson for critical reading of the manuscript.

\section{Funding}

This work was in part supported by the Swiss National Science Foundation, the Swiss Cancer League, Marie Curie Foundation, EuroSyStem and OptiStem.

The authors declare no competing financial interests.

Competing interests statement

The authors declare no competing financial interests.

\section{References}

Ables, J. L., Breunig, J. J., Eisch, A. J. and Rakic, P. (2011). Not(ch) just development: Notch signalling in the adult brain. Nat. Rev. Neurosci. 12, 269283.

Aguirre, A., Rubio, M. E. and Gallo, V. (2010). Notch and EGFR pathway interaction regulates neural stem cell number and self-renewal. Nature 467, 323-327.

Androutsellis-Theotokis, A., Leker, R. R., Soldner, F., Hoeppner, D. J., Ravin, R., Poser, S. W., Rueger, M. A., Bae, S. K., Kittappa, R. and McKay, R. D. (2006). Notch signalling regulates stem cell numbers in vitro and in vivo. Nature 442, 823-826.

Artavanis-Tsakonas, S., Delidakis, C. and Fehon, R. G. (1991). The Notch locus and the cell biology of neuroblast segregation. Annu. Rev. Cell Biol. 7, 427-452.

Austin, C. P., Feldman, D. E., Ida, J. A., Jr and Cepko, C. L. (1995). Vertebrate retinal ganglion cells are selected from competent progenitors by the action of Notch. Development 121, 3637-3650.

Bao, Z. Z. and Cepko, C. L. (1997). The expression and function of Notch pathway genes in the developing rat eye. J. Neurosci. 17, 1425-1434.

Bardin, A. J., Le Borgne, R. and Schweisguth, F. (2004). Asymmetric localization and function of cell-fate determinants: a fly's view. Curr. Opin. Neurobiol. 14, 6-14.

Bardin, A. J., Perdigoto, C. N., Southall, T. D., Brand, A. H. and Schweisguth, F. (2010). Transcriptional control of stem cell maintenance in the Drosophila intestine. Development 137, 705-714.

Barker, N., van Es, J. H., Kuipers, J., Kujala, P., van den Born, M., Cozijnsen, M., Haegebarth, A., Korving, J., Begthel, H., Peters, P. J. et al. (2007). Identification of stem cells in small intestine and colon by marker gene Lgr5. Nature 449, 1003-1007

Bate, M., Rushton, E. and Frasch, M. (1993). A dual requirement for neurogenic genes in Drosophila myogenesis. Dev. Suppl. 1993, 149-161.

Bertrand, J. Y., Chi, N. C., Santoso, B., Teng, S., Stainier, D. Y. and Traver, D. (2010). Haematopoietic stem cells derive directly from aortic endothelium during development. Nature 464, 108-111.

Bigas, A. and Espinosa, L. (2012). Hematopoietic stem cells: to be or Notch to be. Blood 119, 3226-3235.

Biteau, B. and Jasper, H. (2011). EGF signaling regulates the proliferation of intestinal stem cells in Drosophila. Development 138, 1045-1055.

Biteau, B., Hochmuth, C. E. and Jasper, H. (2008). JNK activity in somatic stem cells causes loss of tissue homeostasis in the aging Drosophila gut. Cell Stem Cell 3, 442-455.

Bjornson, C. R., Cheung, T. H., Liu, L., Tripathi, P. V., Steeper, K. M. and Rando, T. A. (2012). Notch signaling is necessary to maintain quiescence in adult muscle stem cells. Stem Cells 30, 232-242.

Boisset, J. C., van Cappellen, W., Andrieu-Soler, C., Galjart, N., Dzierzak, E. and Robin, C. (2010). In vivo imaging of haematopoietic cells emerging from the mouse aortic endothelium. Nature 464, 116-120.

Brack, A. S. and Rando, T. A. (2012). Tissue-specific stem cells: lessons from the skeletal muscle satellite cell. Cell Stem Cell 10, 504-514.

Brack, A. S., Conboy, I. M., Conboy, M. J., Shen, J. and Rando, T. A. (2008). A temporal switch from notch to Wnt signaling in muscle stem cells is necessary for normal adult myogenesis. Cell Stem Cell 2, 50-59. 
Bray, S. (1998). Notch signalling in Drosophila: three ways to use a pathway. Semin. Cell Dev. Biol. 9, 591-597.

Bray, S. J. (2006). Notch signalling: a simple pathway becomes complex. Nat. Rev. Mol. Cell Biol. 7, 678-689.

Bröhl, D., Vasyutina, E., Czajkowski, M. T., Griger, J., Rassek, C., Rahn, H. P., Purfürst, B., Wende, H. and Birchmeier, C. (2012). Colonization of the satellite cell niche by skeletal muscle progenitor cells depends on Notch signals. Dev. Cell 23, 469-481.

Buas, M. F., Kabak, S. and Kadesch, T. (2010). The Notch effector Hey1 associates with myogenic target genes to repress myogenesis. J. Biol. Chem. 285, 1249-1258

Buckingham, M. and Vincent, S. D. (2009). Distinct and dynamic myogenic populations in the vertebrate embryo. Curr. Opin. Genet. Dev. 19, 444-453.

Burns, C. E., Traver, D., Mayhall, E., Shepard, J. L. and Zon, L. I. (2005). Hematopoietic stem cell fate is established by the Notch-Runx pathway. Genes Dev. 19, 2331-2342

Butler, J. M., Nolan, D. J., Vertes, E. L., Varnum-Finney, B., Kobayashi, H., Hooper, A. T., Seandel, M., Shido, K., White, I. A., Kobayashi, M. et al. (2010). Endothelial cells are essential for the self-renewal and repopulation of Notch-dependent hematopoietic stem cells. Cell Stem Cell 6, 251-264.

Calvi, L. M., Adams, G. B., Weibrecht, K. W., Weber, J. M., Olson, D. P., Knight, M. C., Martin, R. P., Schipani, E., Divieti, P., Bringhurst, F. R. et al. (2003). Osteoblastic cells regulate the haematopoietic stem cell niche. Nature 425, 841-846.

Chambers, C. B., Peng, Y., Nguyen, H., Gaiano, N., Fishell, G. and Nye, J. S. (2001). Spatiotemporal selectivity of response to Notch1 signals in mammalian forebrain precursors. Development 128, 689-702

Chapouton, P., Skupien, P., Hesl, B., Coolen, M., Moore, J. C., Madelaine, R., Kremmer, E., Faus-Kessler, T., Blader, P., Lawson, N. D. et al. (2010). Notch activity levels control the balance between quiescence and recruitment of adult neural stem cells. J. Neurosci. 30, 7961-7974

Chen, M. J., Yokomizo, T., Zeigler, B. M., Dzierzak, E. and Speck, N. A. (2009) Runx1 is required for the endothelial to haematopoietic cell transition but not thereafter. Nature 457, 887-891.

Chitnis, A., Henrique, D., Lewis, J., Ish-Horowicz, D. and Kintner, C. (1995). Primary neurogenesis in Xenopus embryos regulated by a homologue of the Drosophila neurogenic gene Delta. Nature 375, 761-766

Clements, W. K., Kim, A. D., Ong, K. G., Moore, J. C., Lawson, N. D. and Traver, D. (2011). A somitic Wnt16/Notch pathway specifies haematopoietic stem cells. Nature 474, 220-224.

Coffman, C. R., Skoglund, P., Harris, W. A. and Kintner, C. R. (1993). Expression of an extracellular deletion of Xotch diverts cell fate in Xenopus embryos. Cell 73, 659-671.

Conboy, I. M., Conboy, M. J., Smythe, G. M. and Rando, T. A. (2003). Notchmediated restoration of regenerative potential to aged muscle. Science $\mathbf{3 0 2}$ 1575-1577.

Cumano, A. and Godin, I. (2007). Ontogeny of the hematopoietic system. Annu. Rev. Immunol. 25, 745-785.

Dahlqvist, C., Blokzijl, A., Chapman, G., Falk, A., Dannaeus, K., Ibâñez, C. F. and Lendahl, U. (2003). Functional Notch signaling is required for BMP4induced inhibition of myogenic differentiation. Development 130, 6089-6099.

de Jong, J. L. and Zon, L. I. (2005). Use of the zebrafish system to study primitive and definitive hematopoiesis. Annu. Rev. Genet. 39, 481-501.

de Navascués, J., Perdigoto, C. N., Bian, Y., Schneider, M. H., Bardin, A. J. Martínez-Arias, A. and Simons, B. D. (2012). Drosophila midgut homeostasis involves neutral competition between symmetrically dividing intestinal stem cells. $E M B O$ J. 31, 2473-2485.

Del Bene, F., Wehman, A. M., Link, B. A. and Baier, H. (2008). Regulation of neurogenesis by interkinetic nuclear migration through an apical-basal notch gradient. Cell 134, 1055-1065.

Delaney, C., Heimfeld, S., Brashem-Stein, C., Voorhies, H., Manger, R. L. and Bernstein, I. D. (2010). Notch-mediated expansion of human cord blood progenitor cells capable of rapid myeloid reconstitution. Nat. Med. 16, 232-236.

Dong, Z., Yang, N., Yeo, S. Y., Chitnis, A. and Guo, S. (2012). Intralineage directional Notch signaling regulates self-renewal and differentiation of asymmetrically dividing radial glia. Neuron $\mathbf{7 4 , 6 5 - 7 8 . ~}$

Duarte, A., Hirashima, M., Benedito, R., Trindade, A., Diniz, P., Bekman, E., Costa, L., Henrique, D. and Rossant, J. (2004). Dosage-sensitive requirement for mouse D\|l4 in artery development. Genes Dev. 18, 2474-2478.

Dumortier, A., Wilson, A., MacDonald, H. R. and Radtke, F. (2005). Paradigms of notch signaling in mammals. Int. J. Hematol. 82, 277-284.

Edmondson, D. G., Lyons, G. E., Martin, J. F. and Olson, E. N. (1994). Mef2 gene expression marks the cardiac and skeletal muscle lineages during mouse embryogenesis. Development 120, 1251-1263.

Egger, B., Gold, K. S. and Brand, A. H. (2011). Regulating the balance between symmetric and asymmetric stem cell division in the developing brain. Fly (Austin) 5, 237-241.

Ehm, O., Göritz, C., Covic, M., Schäffner, I., Schwarz, T. J., Karaca, E., Kempkes, B., Kremmer, E., Pfrieger, F. W., Espinosa, L. et al. (2010).
RBPJkappa-dependent signaling is essential for long-term maintenance of neural stem cells in the adult hippocampus. J. Neurosci. 30, 13794-13807.

Ellisen, L. W., Bird, J., West, D. C., Soreng, A. L., Reynolds, T. C., Smith, S. D. and Sklar, J. (1991). TAN-1, the human homolog of the Drosophila notch gene, is broken by chromosomal translocations in T lymphoblastic neoplasms. Cell $\mathbf{6 6}$, 649-661.

Fischer, A., Schumacher, N., Maier, M., Sendtner, M. and Gessler, M. (2004). The Notch target genes Hey1 and Hey2 are required for embryonic vascular development. Genes Dev. 18, 901-911.

Fortini, M. E. (2012). Introduction - Notch in development and disease. Semin Cell Dev. Biol. 23, 419-420

Fre, S., Huyghe, M., Mourikis, P., Robine, S., Louvard, D. and ArtavanisTsakonas, S. (2005). Notch signals control the fate of immature progenitor cells in the intestine. Nature 435, 964-968.

Fre, S., Pallavi, S. K., Huyghe, M., Laé, M., Janssen, K. P., Robine, S., Artavanis-Tsakonas, S. and Louvard, D. (2009). Notch and Wnt signals cooperatively control cell proliferation and tumorigenesis in the intestine. Proc. Natl. Acad. Sci. USA 106, 6309-6314.

Fre, S., Hannezo, E., Sale, S., Huyghe, M., Lafkas, D., Kissel, H., Louvi, A., Greve, J., Louvard, D. and Artavanis-Tsakonas, S. (2011). Notch lineages and activity in intestinal stem cells determined by a new set of knock-in mice. PLOS ONE 6, e25785.

Furukawa, T., Maruyama, S., Kawaichi, M. and Honjo, T. (1992). The Drosophila homolog of the immunoglobulin recombination signal-binding protein regulates peripheral nervous system development. Cel/ 69, 1191-1197.

Gaiano, N., Nye, J. S. and Fishell, G. (2000). Radial glial identity is promoted by Notch1 signaling in the murine forebrain. Neuron 26, 395-404.

Givogri, M. I., de Planell, M., Galbiati, F., Superchi, D., Gritti, A., Vescovi, A., de Vellis, J. and Bongarzone, E. R. (2006). Notch signaling in astrocytes and neuroblasts of the adult subventricular zone in health and after cortical injury. Dev. Neurosci. 28, 81-91.

Grandbarbe, L., Bouissac, J., Rand, M., Hrabé de Angelis, M., ArtavanisTsakonas, S. and Mohier, E. (2003). Delta-Notch signaling controls the generation of neurons/glia from neural stem cells in a stepwise process. Development 130, 1391-1402.

Gustafsson, M. V., Zheng, X., Pereira, T., Gradin, K., Jin, S., Lundkvist, J., Ruas, J. L., Poellinger, L., Lendahl, U. and Bondesson, M. (2005). Hypoxia requires notch signaling to maintain the undifferentiated cell state. Dev. Cell $\mathbf{9}$, 617-628.

Hadjidakis, D. J. and Androulakis, I. I. (2006). Bone remodeling. Ann. N. Y. Acad. Sci. 1092, 385-396.

Hadland, B. K., Huppert, S. S., Kanungo, J., Xue, Y., Jiang, R., Gridley, T., Conlon, R. A., Cheng, A. M., Kopan, R. and Longmore, G. D. (2004). A requirement for Notch1 distinguishes 2 phases of definitive hematopoiesis during development. Blood 104, 3097-3105.

Heitzler, P. (2010). Biodiversity and noncanonical Notch signaling. Curr. Top. Dev. Biol. 92, 457-481.

Henrique, D., Adam, J., Myat, A., Chitnis, A., Lewis, J. and Ish-Horowicz, D. (1995). Expression of a Delta homologue in prospective neurons in the chick. Nature 375, 787-790.

Henrique, D., Hirsinger, E., Adam, J., Le Roux, I., Pourquié, O., Ish-Horowicz, D. and Lewis, J. (1997). Maintenance of neuroepithelial progenitor cells by Delta-Notch signalling in the embryonic chick retina. Curr. Biol. 7, 661-670.

Imayoshi, I., Sakamoto, M., Yamaguchi, M., Mori, K. and Kageyama, R. (2010). Essential roles of Notch signaling in maintenance of neural stem cells in developing and adult brains. J. Neurosci. 30, 3489-3498.

Irvin, D. K., Nakano, I., Paucar, A. and Kornblum, H. I. (2004). Patterns of Jagged1, Jagged2, Delta-like 1 and Delta-like 3 expression during late embryonic and postnatal brain development suggest multiple functional roles in progenitors and differentiated cells. J. Neurosci. Res. 75, 330-343.

Ishibashi, M., Moriyoshi, K., Sasai, Y., Shiota, K., Nakanishi, S. and Kageyama, R. (1994). Persistent expression of helix-loop-helix factor HES-1 prevents mammalian neural differentiation in the central nervous system. EMBO J. 13, 1799-1805.

Iso, T., Kedes, L. and Hamamori, Y. (2003). HES and HERP families: multiple effectors of the Notch signaling pathway. J. Cell. Physiol. 194, 237-255.

Itoh, M., Kim, C. H., Palardy, G., Oda, T., Jiang, Y. J., Maust, D., Yeo, S. Y. Lorick, K., Wright, G. J., Ariza-McNaughton, L. et al. (2003). Mind bomb is a ubiquitin ligase that is essential for efficient activation of Notch signaling by Delta. Dev. Cell 4, 67-82

Jan, Y. N. and Jan, L. Y. (1994). Genetic control of cell fate specification in Drosophila peripheral nervous system. Annu. Rev. Genet. 28, 373-393.

Karanu, F. N., Murdoch, B., Gallacher, L., Wu, D. M., Koremoto, M., Sakano, S. and Bhatia, M. (2000). The notch ligand jagged-1 represents a novel growth factor of human hematopoietic stem cells. J. Exp. Med. 192, 1365-1372.

Kassar-Duchossoy, L., Gayraud-Morel, B., Gomès, D., Rocancourt, D., Buckingham, M., Shinin, V. and Tajbakhsh, S. (2004). Mrf4 determines skeletal muscle identity in Myf5:Myod double-mutant mice. Nature 431, 466471 
Kassar-Duchossoy, L., Giacone, E., Gayraud-Morel, B., Jory, A., Gomès, D. and Tajbakhsh, S. (2005). Pax3/Pax7 mark a novel population of primitive myogenic cells during development. Genes Dev. 19, 1426-1431.

Kim, T. H. and Shivdasani, R. A. (2011). Genetic evidence that intestinal Notch functions vary regionally and operate through a common mechanism of Math1 repression. J. Biol. Chem. 286, 11427-11433.

Kissa, K. and Herbomel, P. (2010). Blood stem cells emerge from aortic endothelium by a novel type of cell transition. Nature 464, 112-115.

Knust, E. and Campos-Ortega, J. A. (1989). The molecular genetics of early neurogenesis in Drosophila melanogaster Bioessays 11, 95-100.

Koo, B. K., Lim, H. S., Song, R., Yoon, M. J., Yoon, K. J., Moon, J. S., Kim, Y. W., Kwon, M. C., Yoo, K. W., Kong, M. P. et al. (2005). Mind bomb 1 is essential for generating functional Notch ligands to activate Notch. Development 132, 3459-3470

Kopan, R. and Ilagan, M. X. (2009). The canonical Notch signaling pathway: unfolding the activation mechanism. Cell 137, 216-233.

Kopan, R., Nye, J. S. and Weintraub, H. (1994). The intracellular domain of mouse Notch: a constitutively activated repressor of myogenesis directed at the basic helix-loop-helix region of MyoD. Development 120, 2385-2396.

Korinek, V., Barker, N., Moerer, P., van Donselaar, E., Huls, G., Peters, P. J. and Clevers, H. (1998). Depletion of epithelial stem-cell compartments in the small intestine of mice lacking Tcf-4. Nat. Genet. 19, 379-383.

Krebs, L. T., Xue, Y., Norton, C. R., Shutter, J. R., Maguire, M., Sundberg, J. P., Gallahan, D., Closson, V., Kitajewski, J., Callahan, R. et al. (2000). Notch signaling is essential for vascular morphogenesis in mice. Genes Dev. 14, 13431352.

Krebs, L. T., Shutter, J. R., Tanigaki, K., Honjo, T., Stark, K. L. and Gridley, T. (2004). Haploinsufficient lethality and formation of arteriovenous malformations in Notch pathway mutants. Genes Dev. 18, 2469-2473.

Kumano, K., Chiba, S., Kunisato, A., Sata, M., Saito, T., NakagamiYamaguchi, E., Yamaguchi, T., Masuda, S., Shimizu, K., Takahashi, T. et al. (2003). Notch1 but not Notch2 is essential for generating hematopoietic stem cells from endothelial cells. Immunity 18, 699-711.

Lam, E. Y., Hall, C. J., Crosier, P. S., Crosier, K. E. and Flores, M. V. (2010). Live imaging of Runx 1 expression in the dorsal aorta tracks the emergence of blood progenitors from endothelial cells. Blood 116, 909-914.

Lee, C. Y., Vogeli, K. M., Kim, S. H., Chong, S. W., Jiang, Y. J., Stainier, D. Y. and Jin, S. W. (2009). Notch signaling functions as a cell-fate switch between the endothelial and hematopoietic lineages. Curr. Biol. 19, 1616-1622.

Limbourg, F. P., Takeshita, K., Radtke, F., Bronson, R. T., Chin, M. T. and Liao, J. K. (2005). Essential role of endothelial Notch1 in angiogenesis. Circulation 111, 1826-1832.

Lindsell, C. E., Shawber, C. J., Boulter, J. and Weinmaster, G. (1995). Jagged: a mammalian ligand that activates Notch1. Cell 80, 909-917.

Liu, J., Sato, C., Cerletti, M. and Wagers, A. (2010a). Notch signaling in the regulation of stem cell self-renewal and differentiation. Curr. Top. Dev. Biol. 92 367-409.

Liu, W., Singh, S. R. and Hou, S. X. (2010b). JAK-STAT is restrained by Notch to control cell proliferation of the Drosophila intestinal stem cells. J. Cell. Biochem. 109, 992-999

Lugert, S., Basak, O., Knuckles, P., Haussler, U., Fabel, K., Götz, M., Haas, C. A., Kempermann, G., Taylor, V. and Giachino, C. (2010). Quiescent and active hippocampal neural stem cells with distinct morphologies respond selectively to physiological and pathological stimuli and aging. Cell Stem Cell 6 445-456.

Lütolf, S., Radtke, F., Aguet, M., Suter, U. and Taylor, V. (2002). Notch1 is required for neuronal and glial differentiation in the cerebellum. Development 129, 373-385

Maillard, I., Koch, U., Dumortier, A., Shestova, O., Xu, L., Sai, H., Pross, S. E. Aster, J. C., Bhandoola, A., Radtke, F. et al. (2008). Canonical notch signaling is dispensable for the maintenance of adult hematopoietic stem cells. Cell Stem Cell 2, 356-366.

Mancini, S. J., Mantei, N., Dumortier, A., Suter, U., MacDonald, H. R. and Radtke, F. (2005). Jagged1-dependent Notch signaling is dispensable for hematopoietic stem cell self-renewal and differentiation. Blood 105, 2340-2342.

Micchelli, C. A. and Perrimon, N. (2006). Evidence that stem cells reside in the adult Drosophila midgut epithelium. Nature 439, 475-479.

Milano, J., McKay, J., Dagenais, C., Foster-Brown, L., Pognan, F., Gadient, R., Jacobs, R. T., Zacco, A., Greenberg, B. and Ciaccio, P. J. (2004). Modulation of notch processing by gamma-secretase inhibitors causes intestinal goblet cell metaplasia and induction of genes known to specify gut secretory lineage differentiation. Toxicol. Sci. 82, 341-358.

Milner, L. A., Kopan, R., Martin, D. I. and Bernstein, I. D. (1994). A human homologue of the Drosophila developmental gene, Notch, is expressed in CD34+ hematopoietic precursors. Blood 83, 2057-2062.

Mourikis, P., Sambasivan, R., Castel, D., Rocheteau, P., Bizzarro, V. and Tajbakhsh, S. (2012). A critical requirement for notch signaling in maintenance of the quiescent skeletal muscle stem cell state. Stem Cells 30, 243-252.

Nakagawa, M., Ichikawa, M., Kumano, K., Goyama, S., Kawazu, M., Asai, T., Ogawa, S., Kurokawa, M. and Chiba, S. (2006). AML1/Runx1 rescues
Notch1-null mutation-induced deficiency of para-aortic splanchnopleural hematopoiesis. Blood 108, 3329-3334.

Neumüller, R. A. and Knoblich, J. A. (2009). Dividing cellular asymmetry: asymmetric cell division and its implications for stem cells and cancer. Genes Dev. 23, 2675-2699.

Nottingham, W. T., Jarratt, A., Burgess, M., Speck, C. L., Cheng, J. F., Prabhakar, S., Rubin, E. M., Li, P. S., Sloane-Stanley, J., Kong-A-San, J. et al. (2007). Runx1-mediated hematopoietic stem-cell emergence is controlled by a Gata/Ets/SCL-regulated enhancer. Blood 110, 4188-4197.

Nyfeler, Y., Kirch, R. D., Mantei, N., Leone, D. P., Radtke, F., Suter, U. and Taylor, V. (2005). Jagged1 signals in the postnatal subventricular zone are required for neural stem cell self-renewal. EMBO J. 24, 3504-3515.

Ohata, S., Aoki, R., Kinoshita, S., Yamaguchi, M., Tsuruoka-Kinoshita, S., Tanaka, H., Wada, H., Watabe, S., Tsuboi, T., Masai, I. et al. (2011). Dua roles of Notch in regulation of apically restricted mitosis and apicobasal polarity of neuroepithelial cells. Neuron 69, 215-230.

Ohlstein, B. and Spradling, A. (2006). The adult Drosophila posterior midgut is maintained by pluripotent stem cells. Nature 439, 470-474

Ohlstein, B. and Spradling, A. (2007). Multipotent Drosophila intestinal stem cells specify daughter cell fates by differential notch signaling. Science $\mathbf{3 1 5}, \mathbf{9 8 8 -}$ 992.

Ohtsuka, T., Sakamoto, M., Guillemot, F. and Kageyama, R. (2001). Roles of the basic helix-loop-helix genes Hes1 and Hes5 in expansion of neural stem cells of the developing brain. J. Biol. Chem. 276, 30467-30474.

Ono, Y., Calhabeu, F., Morgan, J. E., Katagiri, T., Amthor, H. and Zammit, P. S. (2011). BMP signalling permits population expansion by preventing premature myogenic differentiation in muscle satellite cells. Cell Death Differ. 18, 222-234.

Park, H. C. and Appel, B. (2003). Delta-Notch signaling regulates oligodendrocyte specification. Development 130, 3747-3755.

Pellegrinet, L., Rodilla, V., Liu, Z., Chen, S., Koch, U., Espinosa, L., Kaestner, K. H., Kopan, R., Lewis, J. and Radtke, F. (2011). D\|l1- and dll4-mediated notch signaling are required for homeostasis of intestinal stem cells. Gastroenterology 140, 1230-1240

Perdigoto, C. N., Schweisguth, F. and Bardin, A. J. (2011). Distinct levels of Notch activity for commitment and terminal differentiation of stem cells in the adult fly intestine. Development 138, 4585-4595

Pierfelice, T., Alberi, L. and Gaiano, N. (2011). Notch in the vertebrate nervous system: an old dog with new tricks. Neuron 69, 840-855.

Pinto, D., Gregorieff, A., Begthel, H. and Clevers, H. (2003). Canonical Wnt signals are essential for homeostasis of the intestinal epithelium. Genes Dev. 17, 1709-1713

Poulson, D. F. (1937). Chromosomal deficiencies and the embryonic development of Drosophila melanogaster. Proc. Natl. Acad. Sci. USA 23, 133-137.

Powell, A. E., Wang, Y., Li, Y., Poulin, E. J., Means, A. L., Washington, M. K., Higginbotham, J. N., Juchheim, A., Prasad, N., Levy, S. E. et al. (2012). The pan-ErbB negative regulator Lrig1 is an intestinal stem cell marker that functions as a tumor suppressor. Cell 149, 146-158

Radtke, F., Wilson, A., Stark, G., Bauer, M., van Meerwijk, J., MacDonald, H. R. and Aguet, M. (1999). Deficient T cell fate specification in mice with an induced inactivation of Notch1. Immunity 10, 547-558.

Radtke, F., Fasnacht, N. and Macdonald, H. R. (2010). Notch signaling in the immune system. Immunity 32, 14-27.

Relaix, F., Rocancourt, D., Mansouri, A. and Buckingham, M. (2005). A Pax3/Pax7-dependent population of skeletal muscle progenitor cells. Nature 435, 948-953

Riccio, O., van Gijn, M. E., Bezdek, A. C., Pellegrinet, L., van Es, J. H., ZimberStrobl, U., Strobl, L. J., Honjo, T., Clevers, H. and Radtke, F. (2008). Loss of intestinal crypt progenitor cells owing to inactivation of both Notch1 and Notch2 is accompanied by derepression of CDK inhibitors p27Kip1 and p57Kip2. EMBO Rep. 9, 377-383.

Robert-Moreno, A., Espinosa, L., de la Pompa, J. L. and Bigas, A. (2005) RBPjkappa-dependent Notch function regulates Gata2 and is essential for the formation of intra-embryonic hematopoietic cells. Development 132, 11171126

Robert-Moreno, A., Guiu, J., Ruiz-Herguido, C., López, M. E., Inglés-Esteve J., Riera, L., Tipping, A., Enver, T., Dzierzak, E., Gridley, T. et al. (2008). Impaired embryonic haematopoiesis yet normal arterial development in the absence of the Notch ligand Jagged1. EMBO J. 27, 1886-1895.

Rowlinson, J. M. and Gering, M. (2010). Hey2 acts upstream of Notch in hematopoietic stem cell specification in zebrafish embryos. Blood 116, 2046 2056.

Rudnicki, M. A., Schnegelsberg, P. N., Stead, R. H., Braun, T., Arnold, H. H. and Jaenisch, R. (1993). MyoD or Myf-5 is required for the formation of skeletal muscle. Cell 75, 1351-1359.

Sakamoto, M., Hirata, H., Ohtsuka, T., Bessho, Y. and Kageyama, R. (2003) The basic helix-loop-helix genes Hesr1/Hey1 and Hesr2/Hey2 regulate maintenance of neural precursor cells in the brain. J. Biol. Chem. 278, 4480844815.

Sambasivan, R. and Tajbakhsh, S. (2007). Skeletal muscle stem cell birth and properties. Semin. Cell Dev. Biol. 18, 870-882 
Sambasivan, R., Yao, R., Kissenpfennig, A., Van Wittenberghe, L., Paldi, A., Gayraud-Morel, B., Guenou, H., Malissen, B., Tajbakhsh, S. and Galy, A. (2011). Pax7-expressing satellite cells are indispensable for adult skeletal muscle regeneration. Development 138, 3647-3656.

Sangiorgi, E. and Capecchi, M. R. (2008). Bmi1 is expressed in vivo in intestinal stem cells. Nat. Genet. 40, 915-920.

Sato, T., Vries, R. G., Snippert, H. J., van de Wetering, M., Barker, N., Stange, D. E., van Es, J. H., Abo, A., Kujala, P., Peters, P. J. et al. (2009). Single Lgr5 stem cells build crypt-villus structures in vitro without a mesenchymal niche. Nature 459, 262-265.

Sato, T., van Es, J. H., Snippert, H. J., Stange, D. E., Vries, R. G., van den Born, M., Barker, N., Shroyer, N. F., van de Wetering, M. and Clevers, H. (2011). Paneth cells constitute the niche for Lgr5 stem cells in intestinal crypts. Nature 469, 415-418.

Schienda, J., Engleka, K. A., Jun, S., Hansen, M. S., Epstein, J. A., Tabin, C. J., Kunkel, L. M. and Kardon, G. (2006). Somitic origin of limb muscle satellite and side population cells. Proc. Natl. Acad. Sci. USA 103, 945-950.

Schuster-Gossler, K., Cordes, R. and Gossler, A. (2007). Premature myogenic differentiation and depletion of progenitor cells cause severe muscle hypotrophy in Delta1 mutants. Proc. Natl. Acad. Sci. USA 104, 537-542.

Schweisguth, F. and Posakony, J. W. (1992). Suppressor of Hairless, the Drosophila homolog of the mouse recombination signal-binding protein gene, controls sensory organ cell fates. Cell 69, 1199-1212.

Seale, P., Sabourin, L. A., Girgis-Gabardo, A., Mansouri, A., Gruss, P. and Rudnicki, M. A. (2000). Pax7 is required for the specification of myogenic satellite cells. Cell 102, 777-786.

Smith, E., Claudinot, S., Lehal, R., Pellegrinet, L., Barrandon, Y. and Radtke, F. (2012). Generation and characterization of a Notch1 signaling-specific reporter mouse line. Genesis 50, 700-710.

Stier, S., Cheng, T., Dombkowski, D., Carlesso, N. and Scadden, D. T. (2002) Notch1 activation increases hematopoietic stem cell self-renewal in vivo and favors lymphoid over myeloid lineage outcome. Blood 99, 2369-2378.

Stump, G., Durrer, A., Klein, A. L., Lütolf, S., Suter, U. and Taylor, V. (2002). Notch1 and its ligands Delta-like and Jagged are expressed and active in distinct cell populations in the postnatal mouse brain. Mech. Dev. 114, 153-159.

Takashima, S., Adams, K. L., Ortiz, P. A., Ying, C. T., Moridzadeh, R., Younossi-Hartenstein, A. and Hartenstein, V. (2011). Development of the Drosophila entero-endocrine lineage and its specification by the Notch signaling pathway. Dev. Biol. 353, 161-172.

Taylor, M. K., Yeager, K. and Morrison, S. J. (2007). Physiological Notch signaling promotes gliogenesis in the developing peripheral and central nervous systems. Development 134, 2435-2447.

Tian, H., Biehs, B., Warming, S., Leong, K. G., Rangell, L., Klein, O. D. and de Sauvage, F. J. (2011). A reserve stem cell population in small intestine renders Lgr5-positive cells dispensable. Nature 478, 255-259.

Ueo, T., Imayoshi, I., Kobayashi, T., Ohtsuka, T., Seno, H., Nakase, H., Chiba, T. and Kageyama, R. (2012). The role of Hes genes in intestinal development, homeostasis and tumor formation. Development 139, 1071-1082.

van Es, J. H., van Gijn, M. E., Riccio, O., van den Born, M., Vooijs, M., Begthel, H., Cozijnsen, M., Robine, S., Winton, D. J., Radtke, F. et al. (2005). Notch/gamma-secretase inhibition turns proliferative cells in intestinal crypts and adenomas into goblet cells. Nature 435, 959-963.

VanDussen, K. L. and Samuelson, L. C. (2010). Mouse atonal homolog 1 directs intestinal progenitors to secretory cell rather than absorptive cell fate. Dev. Biol. 346, 215-223

VanDussen, K. L., Carulli, A. J., Keeley, T. M., Patel, S. R., Puthoff, B. J., Magness, S. T., Tran, I. T., Maillard, I., Siebel, C., Kolterud, A. et al. (2012). Notch signaling modulates proliferation and differentiation of intestinal crypt base columnar stem cells. Development 139, 488-497.
Varnum-Finney, B., Xu, L., Brashem-Stein, C., Nourigat, C., Flowers, D., Bakkour, S., Pear, W. S. and Bernstein, I. D. (2000). Pluripotent, cytokinedependent, hematopoietic stem cells are immortalized by constitutive Notch1 signaling. Nat. Med. 6, 1278-1281.

Varnum-Finney, B., Brashem-Stein, C. and Bernstein, I. D. (2003). Combined effects of Notch signaling and cytokines induce a multiple log increase in precursors with lymphoid and myeloid reconstituting ability. Blood 101, 17841789

Varnum-Finney, B., Halasz, L. M., Sun, M., Gridley, T., Radtke, F. and Bernstein, I. D. (2011). Notch2 governs the rate of generation of mouse longand short-term repopulating stem cells. J. Clin. Invest. 121, 1207-1216.

Vasyutina, E., Lenhard, D. C., Wende, H., Erdmann, B., Epstein, J. A. and Birchmeier, C. (2007). RBP-J (Rbpsuh) is essential to maintain muscle progenitor cells and to generate satellite cells. Proc. Natl. Acad. Sci. USA 104, 4443-4448.

Wang, S., Sdrulla, A. D., diSibio, G., Bush, G., Nofziger, D., Hicks, C., Weinmaster, G. and Barres, B. A. (1998). Notch receptor activation inhibits oligodendrocyte differentiation. Neuron 21, 63-75.

Wen, Y., Bi, P., Liu, W., Asakura, A., Keller, C. and Kuang, S. (2012). Constitutive Notch activation upregulates Pax7 and promotes the self-renewal of skeletal muscle satellite cells. Mol. Cell. Biol. 32, 2300-2311.

Wendorff, A. A., Koch, U., Wunderlich, F. T., Wirth, S., Dubey, C., Brüning, J. C., MacDonald, H. R. and Radtke, F. (2010). Hes1 is a critical but contextdependent mediator of canonical Notch signaling in lymphocyte development and transformation. Immunity 33, 671-684.

Whitfield, J. F., Morley, P. and Willick, G. E. (2002). The control of bone growth by parathyroid hormone, leptin, and statins. Crit. Rev. Eukaryot. Gene Expr. 12, 23-52.

Wilson-Rawls, J., Molkentin, J. D., Black, B. L. and Olson, E. N. (1999), Activated notch inhibits myogenic activity of the MADS-Box transcription factor myocyte enhancer factor 2C. Mol. Cell. Biol. 19, 2853-2862.

Wong, V. W., Stange, D. E., Page, M. E., Buczacki, S., Wabik, A., Itami, S., van de Wetering, M., Poulsom, R., Wright, N. A., Trotter, M. W. et al. (2012). Lrig1 controls intestinal stem-cell homeostasis by negative regulation of ErbB signalling. Nat. Cell Biol. 14, 401-408.

Xu, N., Wang, S. Q., Tan, D., Gao, Y., Lin, G. and Xi, R. (2011). EGFR, Wingless and JAK/STAT signaling cooperatively maintain Drosophila intestinal stem cells. Dev. Biol. 354, 31-43.

Yan, K. S., Chia, L. A., Li, X., Ootani, A., Su, J., Lee, J. Y., Su, N., Luo, Y., Heilshorn, S. C., Amieva, M. R. et al. (2012). The intestinal stem cell markers Bmi1 and Lgr5 identify two functionally distinct populations. Proc. Natl. Acad. Sci. USA 109, 466-471.

Yang, Q., Bermingham, N. A., Finegold, M. J. and Zoghbi, H. Y. (2001). Requirement of Math1 for secretory cell lineage commitment in the mouse intestine. Science 294, 2155-2158.

Yang, X., Klein, R., Tian, X., Cheng, H. T., Kopan, R. and Shen, J. (2004). Notch activation induces apoptosis in neural progenitor cells through a p53dependent pathway. Dev. Biol. 269, 81-94.

Yoon, K. J., Koo, B. K., Im, S. K., Jeong, H. W., Ghim, J., Kwon, M. C., Moon, J. S., Miyata, T. and Kong, Y. Y. (2008a). Mind bomb 1-expressing intermediate progenitors generate notch signaling to maintain radial glial cells. Neuron 58, 519-531.

Yoon, M. J., Koo, B. K., Song, R., Jeong, H. W., Shin, J., Kim, Y. W., Kong, Y. Y. and Suh, P. G. (2008b). Mind bomb-1 is essential for intraembryonic hematopoiesis in the aortic endothelium and the subaortic patches. Mol. Cell. Biol. 28, 4794-4804.

Zhang, J., Niu, C., Ye, L., Huang, H., He, X., Tong, W. G., Ross, J., Haug, J., Johnson, T., Feng, J. Q. et al. (2003). Identification of the haematopoietic stem cell niche and control of the niche size. Nature $\mathbf{4 2 5}, 836-841$. 